Swarthmore College

Works

2-15-2002

\title{
C-Cl Bond Fission, Hcl Elimination, And Secondary Radical Decomposition In The 193 Nm Photodissociation Of Allyl Chloride
}

\author{
M. L. Morton \\ L. J. Butler \\ Thomas Alex Stephenson \\ Swarthmore College, tstephe1@swarthmore.edu \\ F. Qi
}

Follow this and additional works at: https://works.swarthmore.edu/fac-chemistry

Part of the Physical Chemistry Commons

Let us know how access to these works benefits you

\section{Recommended Citation}

M. L. Morton, L. J. Butler, Thomas Alex Stephenson, and F. Qi. (2002). "C-Cl Bond Fission, Hcl Elimination, And Secondary Radical Decomposition In The 193 Nm Photodissociation Of Allyl Chloride". Journal Of Chemical Physics. Volume 116, Issue 7. 2763-2775. DOI: 10.1063/1.1433965

https://works.swarthmore.edu/fac-chemistry/7

This work is brought to you for free by Swarthmore College Libraries' Works. It has been accepted for inclusion in Chemistry \& Biochemistry Faculty Works by an authorized administrator of Works. For more information, please contact myworks@swarthmore.edu. 


\section{AIP | The Journal of}

$\mathrm{C}-\mathrm{Cl}$ bond fission, $\mathrm{HCl}$ elimination, and secondary radical decomposition in the $193 \mathrm{~nm}$ photodissociation of allyl chloride

Melita L. Morton, Laurie J. Butler, Thomas A. Stephenson, and Fei Qi

Citation: The Journal of Chemical Physics 116, 2763 (2002); doi: 10.1063/1.1433965

View online: http://dx.doi.org/10.1063/1.1433965

View Table of Contents: http://scitation.aip.org/content/aip/journal/jcp/116/7?ver=pdfcov

Published by the AIP Publishing

\section{AAlP $P$ Re-register for Table of Content Alerts}




\title{
$\mathrm{C}-\mathrm{Cl}$ bond fission, $\mathrm{HCl}$ elimination, and secondary radical decomposition in the $193 \mathrm{~nm}$ photodissociation of allyl chloride
}

\author{
Melita L. Morton and Laurie J. Butler \\ The James Franck Institute and Department of Chemistry, The University of Chicago, \\ Chicago, Illinois 60637 \\ Thomas A. Stephenson \\ Department of Chemistry, Swarthmore College, Swarthmore, Pennsylvania 19081-1397 \\ Fei Qi \\ Chemical Sciences Division, Lawrence Berkeley National Laboratory, Berkeley, California 94720
}

(Received 29 June 2001; accepted 19 November 2001)

\begin{abstract}
The primary photodissociation dynamics of allyl chloride upon excitation at $193 \mathrm{~nm}$ is investigated in a crossed laser-molecular beam scattering apparatus. Tunable vacuum ultraviolet (VUV) photoionization of the products provides a unique ability to learn about the secondary reaction products of the nascent photoproducts formed. The data show evidence for four significant primary reaction channels: a previously unidentified low kinetic energy $\mathrm{C}-\mathrm{Cl}$ bond fission channel producing unstable allyl radicals, an excited state $\mathrm{C}-\mathrm{Cl}$ bond fission channel producing $\mathrm{Cl}$ atoms with high translational energy, an $\mathrm{HCl}$ elimination pathway releasing significant energy to product translation to $\mathrm{HCl}$ and its momentum-matched mass 40 partner, and an $\mathrm{HCl}$ elimination channel producing low kinetic energy $\mathrm{HCl}$ products and predominantly unstable mass 40 products. The measured branching of these primary reaction channels of [all $\mathrm{C}-\mathrm{Cl}]:[$ fast $\mathrm{C}-\mathrm{Cl}]$ : [slow $\mathrm{C}-\mathrm{Cl}]$ : [fast $\mathrm{HCl}$ ] : [slow $\mathrm{HCl}$ ] : [all $\mathrm{HCl}$ ] is 1.00: 0.971: 0.029: 0.291: 0.167: 0.458 (where fast refers to the high recoil kinetic energy channels). The high internal energy allyl radicals formed in the slow $\mathrm{C}-\mathrm{Cl}$ fission pathway of allyl chloride further dissociate/isomerize, as do the unstable mass 40 products formed in the $\mathrm{HCl}$ elimination pathways, and these products are investigated. Photoionization efficiency (PIE) curves of the $\mathrm{HCl}$ product suggest that a three-centered elimination mechanism contributes significantly to an observed $\mathrm{HCl}$ elimination reaction. (c) 2002 American Institute of Physics. [DOI: 10.1063/1.1433965]
\end{abstract}

\section{INTRODUCTION}

A fundamental goal of chemistry is to gain predictive ability for reactions where more than one product channel is energetically possible. Extending this search for understanding beyond primary dissociation pathways, chemists would like to be able to gain qualitative predictive ability for secondary reactions of radical products as well. The reactions such as the bond fission and molecular elimination pathways of allyl chloride investigated in a crossed laser-molecular beam apparatus (and therefore without solution effects) can help develop such predictive ability. Allyl chloride, excited by $193 \mathrm{~nm}$ light to the nominally $\pi \pi^{*}$ state, can undergo initial $\mathrm{C}-\mathrm{Cl}$ bond fission or $\mathrm{HCl}$ elimination, and the nascent $\mathrm{C}_{3} \mathrm{H}_{5}$ and $\mathrm{C}_{3} \mathrm{H}_{4}$ primary products can undergo secondary decomposition via competing isomerization or $\mathrm{C}-\mathrm{H}$ bond fission processes that depend on the internal energy of the primary products.

Thus this article seeks to elucidate the competing $\mathrm{HCl}$ elimination channels and $\mathrm{C}-\mathrm{Cl}$ bond fission channels of allyl chloride photolyzed at $193 \mathrm{~nm}$ as well as the secondary dissociation of both the allyl radical produced from $\mathrm{C}-\mathrm{Cl}$ fission and the $\mathrm{C}_{3} \mathrm{H}_{4}$ product from $\mathrm{HCl}$ elimination. See Fig. 1 for a diagram detailing the significant primary and secondary reactions examined in this work. Prior work on the photodissociation of allyl chloride ${ }^{1}$ at $193 \mathrm{~nm}$ identified three competing channels occurring upon $\pi \pi^{*}$ excitation of allyl chlo- ride, one channel for $\mathrm{C}-\mathrm{Cl}$ bond fission and two pathways for $\mathrm{HCl}$ elimination, but did not elucidate the mechanisms for the two $\mathrm{HCl}$ elimination processes identified. Tunable VUV photoionization detection of the $\mathrm{HCl}$ and its momentum-matched $\mathrm{C}_{3} \mathrm{H}_{4}$ product in the present work allows us to gain both a crude measure of the level of $\mathrm{HCl}$ vibrational excitation as well as a probe of the secondary dissociation of the $\mathrm{C}_{3} \mathrm{H}_{4}$ products. The reaction also allows us to probe the secondary dissociation of the allyl radical product from a previously undetected low kinetic energy $\mathrm{C}-\mathrm{Cl}$ bond fission channel. Although the $\mathrm{C}-\mathrm{H}$ bond dissociation and isomerization of the allyl radical has been extensively investigated, a dramatic discrepancy remains on the relative heights of the isomerization barrier to 2-propenyl radical and the barrier to the unimolecular dissociation to $\mathrm{H}+$ allene. While the molecular beam photofragment scattering experiments of Y. T. Lee and co-workers ${ }^{2}$ interpret their results using the $48.6 \mathrm{kcal} / \mathrm{mol}$ isomerization barrier of allyl radical to 2-propenyl radical derived from bulk kinetic experiments, ${ }^{3}$ recent theoretical work ${ }^{4}$ calculates the barrier to be about $15 \mathrm{kcal} / \mathrm{mol}$ higher, above instead of below the $\mathrm{C}-\mathrm{H}$ bond fission barrier.

The previous experiments that identified the $\mathrm{C}-\mathrm{Cl}$ bond fission and $\mathrm{HCl}$ elimination reactions observed only one $\mathrm{C}-\mathrm{Cl}$ bond fission pathway, $\mathrm{C}-\mathrm{Cl}$ fission that released a high fraction of the total available energy available into product 


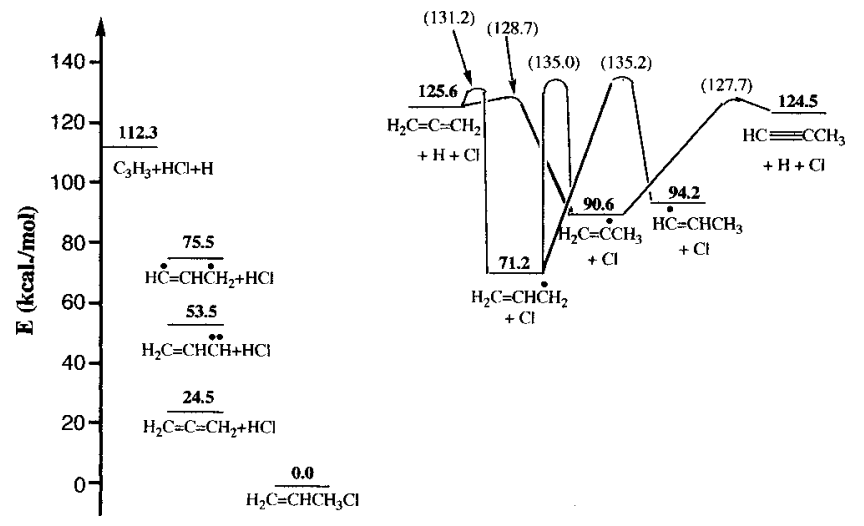

FIG. 1. Energy curve diagram for several of the important primary and secondary product channels in the photodissociation of allyl chloride at 193 $\mathrm{nm}$. Energetics are taken from literature $\Delta \mathrm{H}_{\mathrm{f}, 298 \mathrm{~K}}$ values without conversion to $\Delta \mathrm{H}_{\mathrm{f}, 0 \mathrm{~K}}$. The energetics for the $\mathrm{HCl}$ elimination and $\mathrm{C}-\mathrm{Cl}$ bond fission reactions are taken from various literature values (Refs. 1,19 and 20) and the barrier heights and energetics for the isomerization and $\mathrm{H}$-atom loss reactions of the $\mathrm{C}_{3} \mathrm{H}_{5}$ radicals are taken from the work of Davis et al. (Ref. 4).

translational energy. The authors therefore attributed this reaction to a mechanism involving predissociation via a $n \sigma_{\mathrm{C}-\mathrm{Cl}} *$ repulsive state after excitation to the dominantly $\pi \pi^{*} \mathrm{C}=\mathrm{C}$ excited state surface (with some admixture of $n \sigma^{*}{ }_{\mathrm{C}-\mathrm{Cl}}$ character even in the Franck-Condon region), which would explain the large product recoil velocities. In this work we detect a minor but significant second $\mathrm{C}-\mathrm{Cl}$ fission pathway which imparts much less energy to photofragment recoil. Nascent allyl radicals formed with enough internal energy available can then either isomerize or dissociate, and in our experiments we examine these secondary reaction products as well.

The allyl radical, the product of $\mathrm{C}-\mathrm{Cl}$ fission of allyl chloride, is an important intermediate in many thermal ${ }^{5}$ and combustion $^{6}$ processes, and the unimolecular dissociation of the allyl radical has been closely examined by a number of groups under collisionless conditions. Following UV excitation at $248 \mathrm{~nm}$, two different primary dissociation reactions of the allyl radical were identified in the molecular beam photodissociation experiments of Stranges et al.: $\mathrm{H}$ atom loss to give allene $+\mathrm{H}$ or propyne $+\mathrm{H}(84 \%)$ and $\mathrm{CH}_{3}$ elimination $(16 \%) .{ }^{2}$ Chen and co-workers examined the hot ground state dynamics following internal conversion from the UV-excited allyl radical leading to $\mathrm{C}_{3} \mathrm{H}_{4}$ formation and concluded that two major channels contributed, one via direct $\mathrm{H}$ atom loss leading to allene formation and the other via isomerization to the 2-propenyl radical with subsequent competitive hydrogen loss to yield both allene and propyne. ${ }^{7,8}$ It is these channels that we examine in this work, building on our prior work which formed nascent 2-propenyl radicals directly and probed the branching between the $\mathrm{H}+$ allene and the $\mathrm{H}$ + propyne product channels. We possess the key advantage of being able to disperse the secondary $\mathrm{C}-\mathrm{H}$ dissociation products by the internal energy of the unstable radical which decomposed to generate the product (as we did in our prior work on 2-chloropropene). This ability results from the fact that $\mathrm{C}_{3} \mathrm{H}_{4}$ products produced by $\mathrm{H}$ atom loss from the allyl radical travel with essentially the same velocity as their nascent $\mathrm{C}_{3} \mathrm{H}_{5}$ parents. Therefore, since the arrival time of the mass 40 product identifies the translational energy of the mass 41 radical from which it came, conservation of energy allows us to deduce the internal energy of the dissociating mass 41 species. We measure the photoproduct velocity distributions in a crossed laser-molecular beam apparatus with the added advantage of using the tunable photoionization detection of products available with the synchrotron radiation at the Advanced Light Source (ALS) in Berkeley. ${ }^{9}$ Use of photoionization detection, where daughter ion cracking is not the problem that it is with electron bombardment ionization, enabled us to measure how the branching between the $\mathrm{H}+$ allene and the $\mathrm{H}+$ propyne product channels from the unimolecular dissociation of 2-propenyl changed as a function of internal energy in the radical. We apply the same method to assess whether the high internal energy allyl radicals formed from allyl chloride photodissociation give primarily allene $+\mathrm{H}$ or not.

For the two $\mathrm{HCl}$ elimination pathways previously identified as reactions of allyl chloride after excitation with 193 $\mathrm{nm}$ light, three different mechanisms were considered by Myers et al. [where $E_{\text {avail }}=(h \nu)_{193 \mathrm{~nm}}-\Delta \mathrm{H}_{\mathrm{rxn}}$ ]:

$$
\begin{array}{r}
\mathrm{H}_{2} \mathrm{C}=\mathrm{CHCH}_{2} \mathrm{Cl}+193 \mathrm{~nm} \rightarrow \mathrm{H}_{2} \mathrm{C}=\mathrm{C}=\mathrm{CH}_{2}+\mathrm{HCl}, \\
E_{\text {avail }}=123.4 \mathrm{kcal} / \mathrm{mol}, \\
\mathrm{H}_{2} \mathrm{C}=\mathrm{CHCH}_{2} \mathrm{Cl}+193 \mathrm{~nm} \rightarrow \mathrm{H}_{2} \mathrm{C}=\mathrm{CHC} \mathrm{H}+\mathrm{HCl}, \\
E_{\text {avail }}=94.4 \mathrm{kcal} / \mathrm{mol}, \\
\mathrm{H}_{2} \mathrm{C}=\mathrm{CHCH}_{2} \mathrm{Cl}+193 \mathrm{~nm} \rightarrow \mathrm{HC}=\mathrm{CHCH}_{2}+\mathrm{HCl}, \\
E_{\text {avail }}=72.4 \mathrm{kcal} / \mathrm{mol} .
\end{array}
$$

The large energy partitioning to product recoil for one of the $\mathrm{HCl}$ channels suggested that reaction (1) produces the fragments of this higher kinetic energy $\mathrm{HCl}$ elimination channel. Since Myers et al.'s experiments also demonstrated that increasing the nozzle expansion temperature from $200{ }^{\circ} \mathrm{C}$ to $475^{\circ} \mathrm{C}$ increases the low kinetic energy $\mathrm{HCl}$ elimination channel, Myers proposed that an internal conversion mechanism through a proximal $n \sigma^{*}$ state (or $\pi \sigma^{*}$ state at out-ofplane geometries) might explain the branching to the low kinetic energy channel. The increased bending, reorienting the out-of-plane orbitals of allyl chloride in the hotter molecules, could increase the rate of internal conversion by increasing the coupling of the $\pi \pi^{*}$ and $n \sigma^{*}\left(\pi \sigma^{*}\right)$ states. However, at least one of the $\mathrm{HCl}$ elimination channels in allyl chloride could be occurring via an excited state elimination process. As with our work on the $\mathrm{C}-\mathrm{Cl}$ bond fission processes of allyl chloride, to investigate these competing $\mathrm{HCl}$ elimination processes of allyl chloride we utilized the crossed laser-molecular beam apparatus with tunable vacuum ultraviolet (VUV) photoionization detection of the primary and secondary products.

\section{EXPERIMENT}

These experiments measure the recoil velocity distributions of fragments from the photodissociation of allyl chloride excited at $193.3 \mathrm{~nm}$. We also measure the arrival times of the secondary products from the dissociation of both the vibrationally hot allyl radicals and the $\mathrm{C}_{3} \mathrm{H}_{4}$ products formed 
from the $\mathrm{C}-\mathrm{Cl}$ fission and the $\mathrm{HCl}$ elimination primary product channels respectfully. We carried out the experiments using the rotating-source, fixed-detector molecular beam apparatus on the Chemical Dynamics Beamline at Lawrence Berkeley National Laboratory's Advanced Light Source (ALS). This apparatus is a crossed laser-molecular beam apparatus with the key feature of using tunable VUV photons from the ALS to ionize the neutral photofragments in the detector, rather than the more traditional electron bombardment method. The use of the "soft" photoionization largely prevents photofragments from cracking in the ionization process, allowing easier identification of the neutral photofragments formed in the primary and secondary dissociations. Specific details of this apparatus have been described elsewhere. ${ }^{9}$

The 9\% allyl chloride/helium pulsed molecular beam was generated by bubbling helium through a sample of liquid allyl chloride cooled to $-11{ }^{\circ} \mathrm{C}$ to give a total backing pressure of 760 Torr. The gas mixture was expanded through either a room temperature $\left(22^{\circ} \mathrm{C}\right)$ or lightly heated $\left(50^{\circ} \mathrm{C}\right)$ piezo valve with a nozzle diameter size of $1 \mathrm{~mm}$, operating at $100 \mathrm{~Hz}$. There was no evidence of clusters at the conditions used in these experiments. The parent beam velocity was measured by directing the molecular beam straight into the detector and analyzing the shape of the "hole" formed in the signal by the laser at the parent molecular mass. This yields an average peak molecular beam velocity in the number density distribution, $N(v)$, of $1170 \mathrm{~m} / \mathrm{s}$ and a velocity spread $\left(\Delta v / v_{\text {peak }}\right)$ of 0.09 with $\Delta v$ calculated from the full width at half maximum of $N(v)$.

The laser used in this work is a Lambda Physik LPX-200 excimer laser operating on the $193.3 \mathrm{~nm}$ ArF transition at a laser power of $20 \mathrm{~mJ} /$ pulse. The laser beam, focused to a 2 $\times 4 \mathrm{~mm}^{2}$ spot, intersects the molecular beam at an angle of $90^{\circ}$ to the plane defined by the molecular beam and detector axis. Molecules absorb light and dissociate, imparting recoil kinetic energy to the photofragments, and a small fraction of the products scatter into the detector, traveling $15.2 \mathrm{~cm}$ to the point where they are ionized by tunable VUV radiation from the ALS. The characteristics of the light source have been described in detail elsewhere. ${ }^{9}$ The photofragment time of flight spectra presented in this article were taken with a light source bandwidth of about $4.5 \%$, and the photoionization efficiency spectra were taken with a light source bandwidth of $2.2 \%$. A gas filter filled with about 25 Torr Ar eliminates unwanted higher harmonics of the undulator radiation. For most of the data, a $\mathrm{MgF}_{2}$ window filters out any remaining high-energy photons when the probe energy is below 10.8 $\mathrm{eV}$, but for the photoionization efficiency curves taken at $m / e=36$ and 39 , a LiF window (performing a similar function but with a window extending further into the VUV) was in place.

Ions of the mass of interest are mass-selected using a quadrupole mass filter and counted as a function of total flight time from the interaction region using a Daly detector. The ion flight time constant of $\alpha=5.42 \mu \mathrm{s} / \mathrm{amu}^{1 / 2}$ was used to correct for the flight time $\left(\alpha \sqrt{ } m_{\text {ion }}\right)$ of ions through the mass spectrometer; note that figures show total (ion + neutral) flight times.

\section{RESULTS AND ANALYSIS}

\section{Photofragment time of flight spectroscopy of allyl chloride}

\section{Identification of primary product channels}

The data for the photodissociation of allyl chloride excited at $193 \mathrm{~nm}$ evidence four significant competing product channels: two different $\mathrm{C}-\mathrm{Cl}$ bond fission channels, one producing fast $\mathrm{Cl}$ atoms and a minor one producing slow $\mathrm{Cl}$ atoms, and two different $\mathrm{HCl}$ elimination pathways. This is in contrast to previous work ${ }^{1}$ where the minor $\mathrm{C}-\mathrm{Cl}$ bond fission channel was not identified. Secondary dissociation of the $\mathrm{C}-\mathrm{Cl}$ fission $\mathrm{C}_{3} \mathrm{H}_{5}$ radical product produced with less translational energy also occurs, as does decomposition of the higher internal energy $\mathrm{C}_{3} \mathrm{H}_{4}$ co-fragment formed in the primary $\mathrm{HCl}$ elimination. Since $\mathrm{C}-\mathrm{C}$ fission of the allyl radical as a minor channel was seen by Stranges et al. in their work on the photodissociation of the allyl radical at $248 \mathrm{~nm}$ (but not at $351 \mathrm{~nm})^{2}$ and was also investigated as a possible secondary dissociation channel of the H-I bond fissionproduced allyl radical by Szpunar et al. in their work on the $193 \mathrm{~nm}$ photodissociation of allyl iodide, ${ }^{10}$ we looked for secondary $\mathrm{C}-\mathrm{C}$ fission of the primary reaction products of allyl chloride excited at $193 \mathrm{~nm}$ as well. We did not look for three other possible primary reaction channels of allyl chloride excited at $193 \mathrm{~nm}, \mathrm{C}-\mathrm{H}$ bond fission, $\mathrm{H}_{2}$ elimination, and $\mathrm{C}-\mathrm{CH}_{2} \mathrm{Cl}$ bond fission. The third reaction was investigated prior to this work and no evidence for it was found, ${ }^{1}$ and the large photofragments produced in the former two reactions would be too heavy to recoil out to the detection angles sampled. All of the channels examined in these experiments will be discussed in turn.

\section{C-Cl fission and secondary dissociation of the allyl radical}

In Fig. 2(a) we show the time of flight (TOF) spectrum of $\mathrm{Cl}$ atoms, $m / e=35\left(\mathrm{Cl}^{+}\right)$, collected at a source-detector angle of $15^{\circ}$ for 40000 laser shots, using a photoionization energy of $14 \mathrm{eV}$. (Data at a $30^{\circ}$ angle is reported in the EPAPS supplement to this article. ${ }^{11}$ ) The energy available for product translational and internal energy after $\mathrm{C}-\mathrm{Cl}$ fission of allyl chloride at $193 \mathrm{~nm}$ is $76.8 \mathrm{kcal} / \mathrm{mol}$. Two peaks are clearly evident, one a very sharp narrow peak centered at approximately $80 \mu \mathrm{s}$, the other a broad slow component extending from $\sim 100$ to $\sim 175 \mu \mathrm{s}$. This slow component was not identified in the prior work of Myers et al. on allyl chloride, although a second slow component indicating a second $\mathrm{C}-\mathrm{Cl}$ bond fission channel was seen in the photodissociation of both vinyl chloride ${ }^{12-16}$ and 2-chloropropene. ${ }^{17}$ The significantly better signal-to-noise possible in the experiments undertaken at the ALS and the elimination of daughter fragmentation of $\mathrm{HCl}$ in the soft photoionization detection method allowed observation of this small but definite contribution of the second $\mathrm{C}-\mathrm{Cl}$ bond fission channel at $\mathrm{m} / \mathrm{e}$ $=35$. Indeed, in the prior work by Myers et al. there was a slow component to the $m / e=35$ spectra that was attributed to $\mathrm{HCl}$ daughter ions produced by cracking in the electron bombardment ionization process, but some of this signal 


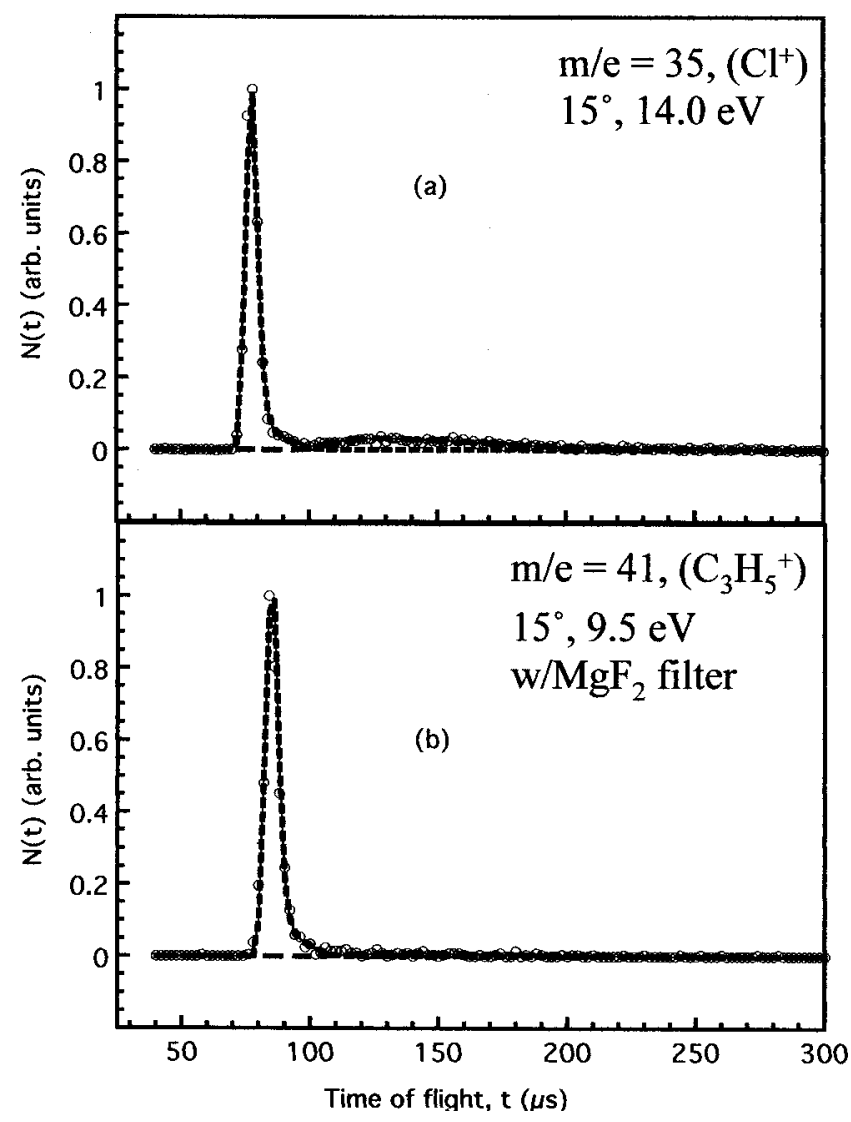

FIG. 2. Time of flight spectra from the $193 \mathrm{~nm} \mathrm{C}-\mathrm{Cl}$ bond fission of allyl chloride. (a) Time of flight spectrum collected with a photoionization energy of $14 \mathrm{eV}$ of the $m / e=35$ signal $(\mathrm{Cl}+)$ at a source-detector angle of $15^{\circ}$. (b) Time of flight spectrum of the $m / e=41$ signal $\left(\mathrm{C}_{3} \mathrm{H}_{3}+\right)$ collected with a photoionization energy of $9.5 \mathrm{eV}$ at a source-detector angle of $15^{\circ}$. Experimental data in both spectra are shown with open circles. Fits shown are calculated from the $\mathrm{C}-\mathrm{Cl}$ bond fission product translational distributions shown in Fig. 3. The sharp peak centered at $\sim 80 \mu$ s in (a) is the high translational energy channel that produces the stable mass 41 momentummatched partners visible in (b). The slow broad portion in (a) is a signal from $\mathrm{Cl}$ atoms that can be momentum matched to the high internal energy allyl radicals that undergo secondary dissociation and so do not appear in the time of flight spectra taken at $m / e=41$. Instead these higher internal energy radicals undergo either $\mathrm{C}-\mathrm{H}$ bond fission to allene $+\mathrm{H}$ or isomerization to the 2-propenyl radical followed by subsequent $\mathrm{H}$ atom loss to yield both allene $+\mathrm{H}$ and propyne $+\mathrm{H}$. However, a small residual signal near $110 \mu \mathrm{s}$ may be from a small part of the allyl radicals formed in the low kinetic energy $\mathrm{C}-\mathrm{Cl}$ fission channel that survive with greater than $60 \mathrm{kcal} / \mathrm{mol}$ of internal energy (Ref. 10).

should have been attributed to the slow $\mathrm{C}-\mathrm{Cl}$ bond fission channel identified in the present experiments.

In Fig. 3, we show the photofragment recoil translational energy distributions, the $P\left(E_{T}\right)$ 's, obtained by forward convolution fitting of the $m / e=35$ TOF spectra. The fast $P\left(E_{T}\right)$, extending from $\sim 16$ to $60 \mathrm{kcal} / \mathrm{mol}$, resembles closely the $P\left(E_{T}\right)$ used by Myers et al. to fit their allyl chloride $\mathrm{C}-\mathrm{Cl}$ bond fission data at $m / e=35$ in average translational energy and shape, and peaks at just slightly lower energy [40 kcal/ mol versus $\sim 45 \mathrm{kcal} / \mathrm{mol}$ for the $P\left(E_{T}\right)$ used by Myers et al.]. It accounts for $97 \%$ of the $\mathrm{C}-\mathrm{Cl}$ bond fission events. Since this $P\left(E_{T}\right)$ peaks at a high translational energy, it indicates that there is a significant exit channel barrier along the reaction coordinate. As observed by Myers et al., such

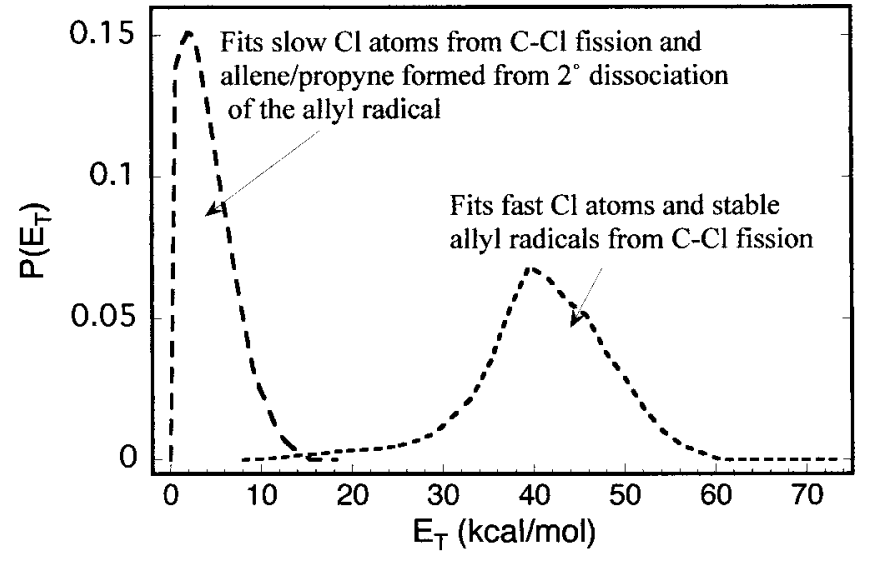

FIG. 3. Product translational energy distributions, $P\left(E_{T}\right)$, for $\mathrm{C}-\mathrm{Cl}$ bond fission in the $193 \mathrm{~nm}$ photodissociation of allyl chloride derived from forward convolution fitting of the signal in Fig. 2(a), scaled to constant area. The solid line represents the high kinetic energy $\mathrm{C}-\mathrm{Cl}$ fission channel that extends from $\sim 70$ to $90 \mu$ s and produces stable allyl radicals as the momentum-matched partners to the $\mathrm{Cl}$ atoms. The dashed line $P\left(E_{T}\right)$ represents the $\mathrm{Cl}$ atoms the low kinetic energy $\mathrm{C}-\mathrm{Cl}$ fission channel, which produce allyl radicals that are either dissociative or that undergo isomerization and then $\mathrm{C}-\mathrm{H}$ bond fission and therefore do not show up at $m / e=41$ [Fig. 2(b)]. However, since $\mathrm{C}-\mathrm{H}$ bond fission does not significantly alter the mass 40's product velocity from the velocity of the allyl radical precursor, we can predict the arrival times of these secondary products in Fig. 4, the $m / e=40$ spectrum, from this $P\left(E_{T}\right)$.

usually indicates that the reaction mechanism involves dissociation along an excited state surface, since ground state simple bond fission processes typically have a negligible barrier to the reverse reaction. The $P\left(E_{T}\right)$ used to fit the slow component at this mass, not seen in the prior molecular beam experiments, extends from $\sim 0$ to $\sim 15 \mathrm{kcal} / \mathrm{mol}$, and peaks at approximately $3 \mathrm{kcal} / \mathrm{mol}$. It accounts for $3 \%$ of the $\mathrm{C}-\mathrm{Cl}$ bond fission events. The slow $\mathrm{C}-\mathrm{Cl}$ fission products from both vinyl chloride and 2-chloropropene were attributed to dissociation after internal conversion to the ground state had occurred, and it is likely that a similar mechanism is occurring in the photodissociation of allyl chloride. This possibility will be examined in more detail in the Discussion section of this article.

In Fig. 2(b), we show the TOF spectra of $m / e=41$ $\left(\mathrm{CH}_{2}=\mathrm{CHCH}_{2}^{+}\right.$, the allyl radical parent ion), collected for 40000 shots at a source-detector angle of $15^{\circ}$ and at an undulator energy of $9.5 \mathrm{eV}$ with the $\mathrm{MgF}_{2}$ window in place to filter out higher energy photons. Only a single sharp peak is visible, which is easily fit by momentum matching it to the fast peak seen at $m / e=35$. The momentum-matched signal to the slow component seen at $m / e=35$ is missing, however, and we suspected (and confirmed, as we explain) that the higher internal energy allyl radicals formed in the initial $\mathrm{C}-\mathrm{Cl}$ bond dissociation undergo secondary dissociation to produce $\mathrm{C}_{3} \mathrm{H}_{4}+\mathrm{H}$. In fitting the $m / e=40$ spectra $\left(\mathrm{C}_{3} \mathrm{H}_{4}^{+}\right.$, see Fig. 4, which will again be examined in the section on $\mathrm{HCl}$ elimination), there was a slow component that could not be assigned to $\mathrm{HCl}$ elimination and was quite well fit by assuming it arose from secondary dissociation of the allyl radical. The TOF of the secondary dissociation products can be fitted using the primary $\mathrm{C}-\mathrm{Cl}$ bond fission $P\left(E_{T}\right)$ since loss of a $\mathrm{H}$ atom from the allyl radical does not significantly 


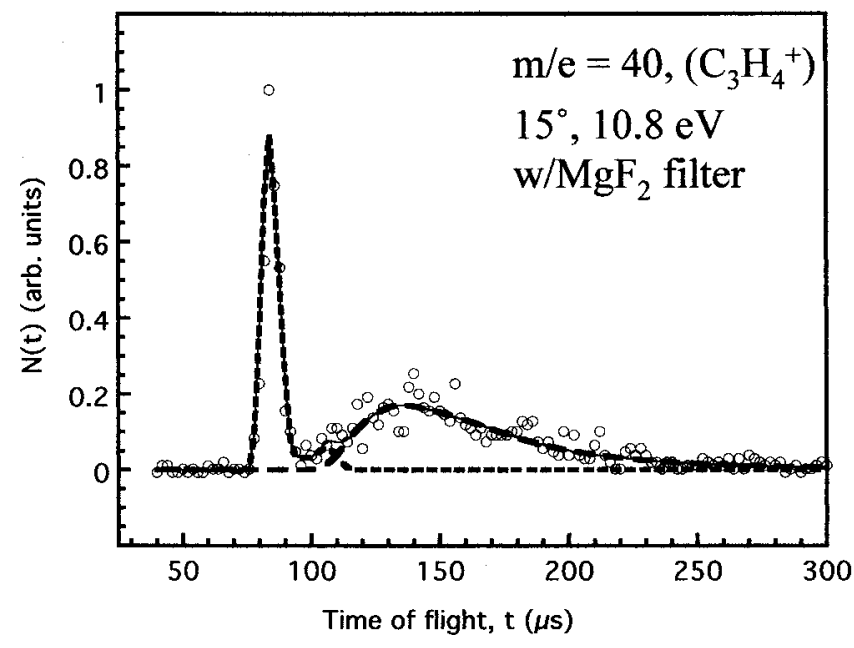

FIG. 4. Time of flight spectrum of the $m / e=40$ signal photoionized at 10.8 $\mathrm{eV}$ at a $15^{\circ}$ source-detector angle. The signal primarily consists of the $\mathrm{C}_{3} \mathrm{H}_{4}$ products from two sources, allene produced from $\mathrm{HCl}$ elimination and allene/propyne produced by secondary dissociation of the allyl radical. The portion of the signal fit in short-dashed line is assigned to $\mathrm{C}_{3} \mathrm{H}_{4}$ fragments resulting from the high kinetic energy $\mathrm{HCl}$ elimination channel of allyl chloride. This fast signal from 74 to $\sim 90 \mu$ s is momentum matched to the fast sharp peak seen at $m / e=36$ (Fig. 6). Fragments with times of arrival of approximately $125 \mu \mathrm{s}$ and longer in the $m / e=40$ TOF spectrum are well fit by the slow $P\left(E_{T}\right)$ used to fit the slow $\mathrm{Cl}$ signal and thus arise from secondary dissociation of the allyl radical produced by $\mathrm{C}-\mathrm{Cl}$ bond fission. However, there is also a signal in an intermediate portion of the $m / e=40$ spectrum that is not fit by either of the above distributions. This signal is hypothesized to be the stable co-fragments of the low kinetic energy $\mathrm{HCl}$ products, of which some are unstable and some are stable to further dissociation.

alter the heavier $\mathrm{C}_{3} \mathrm{H}_{4}$ product's velocity from the velocity of the nascent allyl radical product from $\mathrm{C}-\mathrm{Cl}$ bond fission.

There are two noncyclic mass 40 products energetically available from this secondary dissociation of the allyl radical, propyne $\left(\mathrm{HC} \equiv \mathrm{CCH}_{3}\right)$ and allene $\left(\mathrm{H}_{2} \mathrm{C}=\mathrm{C}=\mathrm{CH}_{2}\right)$. To determine the product(s) formed from the allyl radical, we first took a photoionization efficiency (PIE) curve. This is done by measuring, as a function of energy, the amount of signal at the mass of interest in the time window corresponding to the arrival times of the products one is investigating. For the $m / e=40$ PIE curves, the photoionization energy was varied from 8.2 to $10.5 \mathrm{eV}$ and 60000 shots were taken for each point. Figure 5 shows four curves, one of which (shown in open squares) will be discussed in the section on $\mathrm{HCl}$ elimination. One of the other three curves, that with open circles, shows the PIE curve obtained by integrating the signal observed from 126 to $200 \mu$ s, which corresponds to the arrival times of the secondary dissociation products from the slower allyl radicals. This time window corresponds to the products of dissociating allyl radicals formed in primary $\mathrm{C}-\mathrm{Cl}$ photolysis with 0 to $16 \mathrm{kcal} / \mathrm{mol}$ partitioned to translational energy. Thus, the internal energy of the allyl radicals that dissociate to give this $m / e=40$ signal is between 60.0 and $76.8 \mathrm{kcal} / \mathrm{mol}$. Due to difficulties in measuring the ALS power, we are showing an unnormalized (for power) $\mathrm{m} / \mathrm{e}$ $=40$ PIE curve taken chronologically and are providing for comparison both unnormalized and normalized curves of pure allene (shown in filled circles and diamonds, respec-

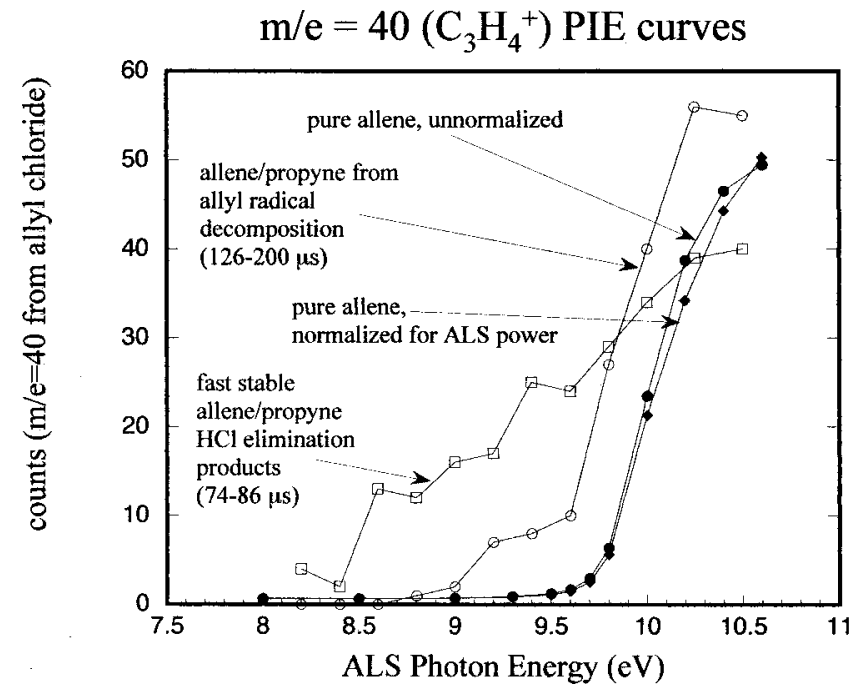

FIG. 5. Photoionization efficiency (PIE) curves. The data is taken with a narrower energy linewidth and corrected for the undulator radiation flux. Data points are shown with error bars with straight-line extrapolations between each point to guide the eye. There are two parts to this graph: the filled circles and diamonds represent data taken by Mueller et al. ${ }^{17}$ for a molecular beam of pure allene as raw data and as normalized for ALS power, respectively, reprinted with permission. These are arbitrarily scaled for comparison to each other and to the raw data from allyl chloride. The second part is the data shown in open squares and circles, with integrated counts given on the $y$-axis. These show PIE data taken for $m / e=40$ produced from the $193 \mathrm{~nm}$ photolysis of allyl chloride, where we integrated over two separate time windows. The open squares show data points for signal integrated over 74-86 $\mu$ s. This corresponds to the fast allene/propyne $\mathrm{HCl}$ elimination products from allyl chloride which are stable to further dissociation. The open circles are data points resulting from integrating signal over a time window extending from 126 to $200 \mu \mathrm{s}$ which corresponds to the arrival times of the slow secondary dissociation product from the allyl radical produced by $\mathrm{C}-\mathrm{Cl}$ fission. The signal from this $m / e=40$ data was collected at a source-detector angle of $15^{\circ}$ and the undulator energy was stepped from 8.2 to $10.5 \mathrm{eV}$ with 60000 shots were taken at each gap energy.

tively). The PIE curve of the secondary dissociation products from the slower allyl radicals suggests that the $\mathrm{H}+$ allene product channel is the dominant one seen since the rise of the curve begins much before $10.36 \mathrm{eV}$, the ionization onset of propyne, and looks quite similar (although redshifted) to the PIE curve of pure allene. The literature ionization of allene is $9.69 \mathrm{eV}$, but the experimental $m / e=40 \mathrm{PIE}$ curve is redshifted from that of room temperature allene because the allene product is partitioned significant vibrational energy from the unimolecular dissociation of the allyl radical. A redshift is expected, as the equilibrium geometry of the ionic form of allene is quite different from that of neutral allene. (The PIE curve of propyne does not, in contrast, undergo a dramatic redshift with just a modest amount of internal energy.)

The small fraction of nascent allyl radicals that might isomerize to the 2-propenyl radical rather than undergo $\mathrm{C}-\mathrm{H}$ bond fission can then also undergo $\mathrm{C}-\mathrm{H}$ bond fission after isomerization to form either propyne or allene, as found by Mueller $e$ e al. ${ }^{17}$ To assess whether the $m / e=40$ spectra include secondary propyne formed from allyl radical that has isomerized to 2-propenyl radical, we took the $m / e=40 \mathrm{TOF}$ spectrum at $10.0 \mathrm{eV}$. In doing so, we can ascertain whether 
the dominant decomposition pathway of the allyl radical in this range of internal energies is direct dissociation to allene $+\mathrm{H}$ or whether a significant fraction isomerize to 2-propenyl radical. We can identify whether there is any significant isomerization of the allyl radical to 2-propenyl radical by comparing the $m / e=40$ spectrum taken with a photoionization energy of $10.0 \mathrm{eV}$, below the literature ionization onset of propyne, with the spectrum taken at a photoionization energy of $10.8 \mathrm{eV}$ (see EPAPS supplement for figures). For the fraction that isomerizes to 2-propenyl, $\mathrm{C}-\mathrm{H}$ bond fission occurs producing propyne $+\mathrm{H}$ and allene $+\mathrm{H}$ statistically with formation of propyne $+\mathrm{H}$ dominating at all energies. ${ }^{17}$ If the isomerization barrier were low, and thus significant propyne was formed from radicals dissociating with a given internal energy, one would observe a depletion of the signal with the corresponding arrival time in the $m / e$ $=40$ spectrum at $10.0 \mathrm{eV}$ (below the propyne I.E.) in comparison with the $10.8 \mathrm{eV}$ spectrum where both allene and propyne give signal. We do not observe such a depletion at any arrival time. In particular, since the transition state for the dissociation of allyl to allene $+\mathrm{H}$ is calculated to be slightly higher in energy (see Fig. 1) than the transition state for the dissociation of 2-propenyl radical to propyne $+\mathrm{H}$, there is an internal energy range that is critical. If the allyl $\rightarrow 2$-propenyl isomerization barrier is as low as that suggested by early kinetic experiments, there is a small internal energy window, from 57.5 to $60.0 \mathrm{kcal} / \mathrm{mol}$, where virtually all the mass 40 products from nascent allyl radical dissociation would be propyne. We do not observe a depletion of signal in the $10.0 \mathrm{eV}$ mass 40 spectrum in the corresponding time window. While the overlapping signal of the allene from $\mathrm{HCl}$ elimination with the mass 40 product resulting from allyl radical decomposition makes a quantitative determination of the relative amount of propyne from this energy window of near-threshold allyl radicals impossible, the shape of the signal arriving at times corresponding to internal energies of $57-60 \mathrm{kcal} / \mathrm{mol}$ in the spectra at 10.0 and $10.8 \mathrm{eV}$ are the same within signal-to-noise, suggesting that any propyne formed from near-threshold energy allyl radicals is, as from the high internal energy allyl radicals, a very minor product.

Finally, since $\mathrm{C}-\mathrm{C}$ fission of the allyl radical as a minor channel was previously identified by Stranges et al., we looked for secondary $\mathrm{C}-\mathrm{C}$ fission of the primary $\mathrm{C}-\mathrm{Cl}$ fission products of allyl chloride excited at $193 \mathrm{~nm}$. While we observed a peak at the mass-to-charge ratio of 26 $(\mathrm{HC} \equiv \mathrm{CH}+),{ }^{11}$ the leading edge was far too fast to be attributable to a one-photon process. (The endothermicity of the net reaction $\mathrm{H}_{2} \mathrm{C}=\mathrm{CHCH}_{2} \mathrm{Cl} \rightarrow \mathrm{Cl}+\mathrm{C}_{2} \mathrm{H}_{2}+\mathrm{CH}_{3}$ is $71.2 \mathrm{kcal} / \mathrm{mol}+46.2 \mathrm{kcal} / \mathrm{mol}=117.3 \mathrm{kcal} / \mathrm{mol}$ and our allyl radicals have much lower internal energy than the photoexcited allyl radicals of Stranges et al.) While it is possible that the signal hides a small contribution from a viable $\mathrm{C}-\mathrm{C}$ fission channel of the allyl radical, data taken at $m / e=15$ $\left(\mathrm{CH}_{3}^{+}\right)$for $3 \times 10^{6}$ laser shots indicates that such a channel, if present, is very minor at the energies used in this experiment. RRKM calculations (using the vibrational frequencies and barrier heights of Wang and co-workers) also predict that the isomerization of allyl to 1-propenyl will not compete

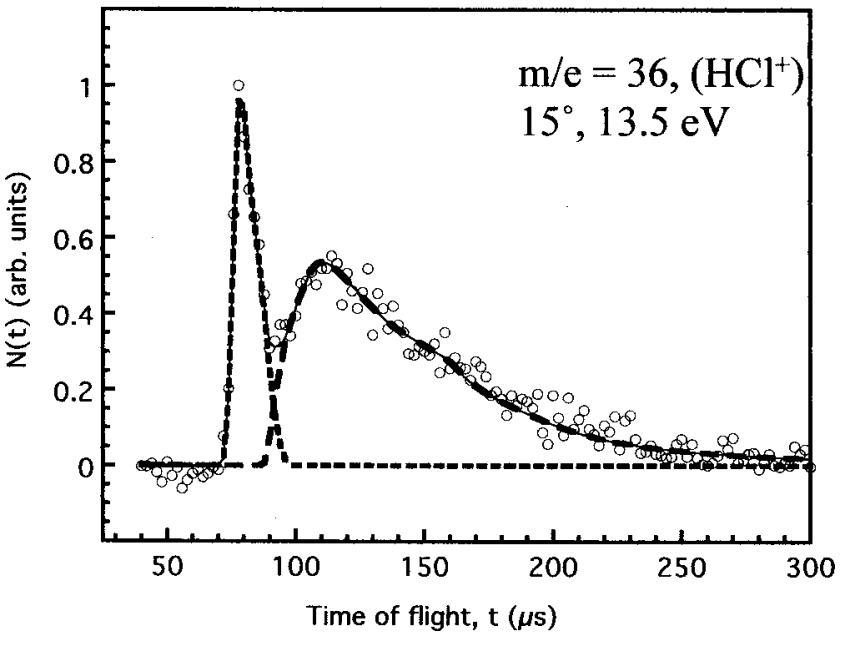

FIG. 6. Time of flight spectrum at a source-detector angle of $15^{\circ}$ of the mass 36 signal corresponding to $\mathrm{HCl}+$, arising from primary $\mathrm{HCl}$ elimination from allyl chloride photoionized at $13.5 \mathrm{eV}$. Experimental data is shown in open circles; the fits for both the high translational energy portion and the low translational energy portions of the spectra were calculated from the $\mathrm{HCl}$ elimination $P\left(E_{T}\right)$ shown in Fig. 7.

effectively against $\mathrm{C}-\mathrm{H}$ bond fission of the allyl radical: $k_{\mathrm{H}+\text { allene }} / k_{\text {isom } \rightarrow 1 \text {-propenyl }}=64: 1$.

\section{$\mathrm{HCl}$ elimination and secondary decomposition of $\mathrm{C}_{3} \mathrm{H}_{4}$ product to propargyl+H}

As stated in the Introduction, one of the reasons we undertook this investigation into the photodissociation of allyl chloride was to attempt to further elucidate the mechanisms for the two $\mathrm{HCl}$ elimination channels. We are able to obtain both the PIE curve of the stable mass 40 products (potentially allene, propyne or cyclopropene, and nascent biradical products that subsequently rearrange, dissociate or isomerize), which are the high translational energy nascent $\mathrm{HCl}$ elimination co-fragments, as well as detect and obtain the PIE curve for the propargyl $+\mathrm{H}$ channel arising from secondary dissociation of the $\mathrm{C}_{3} \mathrm{H}_{4}$ co-fragments in the other lower kinetic energy $\mathrm{HCl}$ elimination pathway. This second $\mathrm{HCl}$ elimination channel partitions less energy to product translation, and so produces mostly mass 40 products with internal energies above the propargyl $+\mathrm{H}$ dissociation limit.

Figure 6 shows the TOF spectrum taken at $m / e=36$ $\left(\mathrm{HCl}^{+}\right)$at a source-detector angle of $15^{\circ}$, collected for 300000 shots and taken with a photoionization energy of $13.5 \mathrm{eV}$. Two peaks are visible, a sharp fast peak centered at about $85 \mu$ s and a large broad peak starting at $\sim 90 \mu$ s with a long slow tail extending out to $\sim 300 \mu \mathrm{s}$. The $P\left(E_{T}\right)$ used to fit these spectra is the solid line shown in Fig. 7. It is a bimodal distribution, and we have scaled it to show the relative abundance of fast and slow $\mathrm{HCl}$ fragments. Both the higher energy portion and the lower energy portion of the distribution are similar to those found by Myers et al. The PIE curve of the $\mathrm{HCl}$ product is shown in Fig. 8. We integrated separately the PIE data in the two time windows seen in the $m / e=36$ spectrum (see Fig. 6), one for the low kinetic energy $\mathrm{HCl}$ elimination channel and one for the high kinetic energy $\mathrm{HCl}$ elimination channel. It is obvious that the photo- 


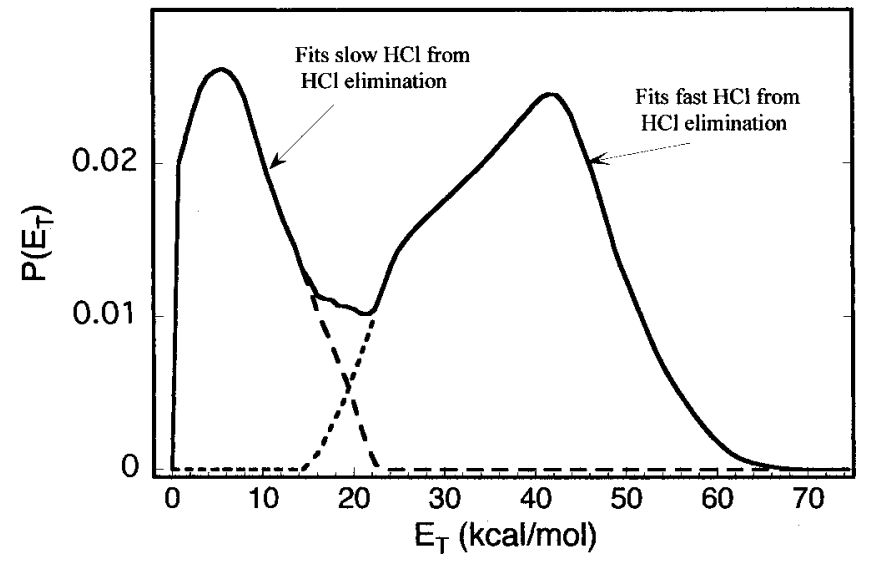

FIG. 7. Product translational energy distribution, $P\left(E_{T}\right)$, for $\mathrm{HCl}$ elimination in allyl chloride photolysed at $193 \mathrm{~nm}$, derived from forward convolution fitting of the signal in Fig. 6. The solid line shows the full $\mathrm{HCl}$ bimodal distribution, while the dotted lines indicate the separation of the high and low kinetic energy $\mathrm{HCl}$ elimination channels as seen in Fig. 6. Note that in both vinyl chloride and 2-chloropropene the $\mathrm{HCl} P\left(E_{T}\right)$ was a single broad distribution, while two different elimination pathways are evident in the 193 $\mathrm{nm}$ photolysed reactions of allyl chloride. The branching between the high kinetic energy $\mathrm{HCl}$ elimination channel and the low kinetic energy $\mathrm{HCl}$ elimination channel in allyl chloride is 0.635:0.365.

ionization onset of the $\mathrm{HCl}$ fragments from the low kinetic energy channel is redshifted more than for the $\mathrm{HCl}$ fragments from the high kinetic energy $\mathrm{HCl}$ elimination channel. In the discussion we analyze the PIE curves to help evaluate the differing reaction mechanisms for $\mathrm{HCl}$ elimination between allyl chloride and that seen with vinyl chloride and 2-chloropropene; comparison of the PIE curves of the $\mathrm{HCl}$ fragment formed in the $\mathrm{HCl}$ elimination shows that the $\mathrm{HCl}$ from allyl chloride is formed with significantly lower vibra-

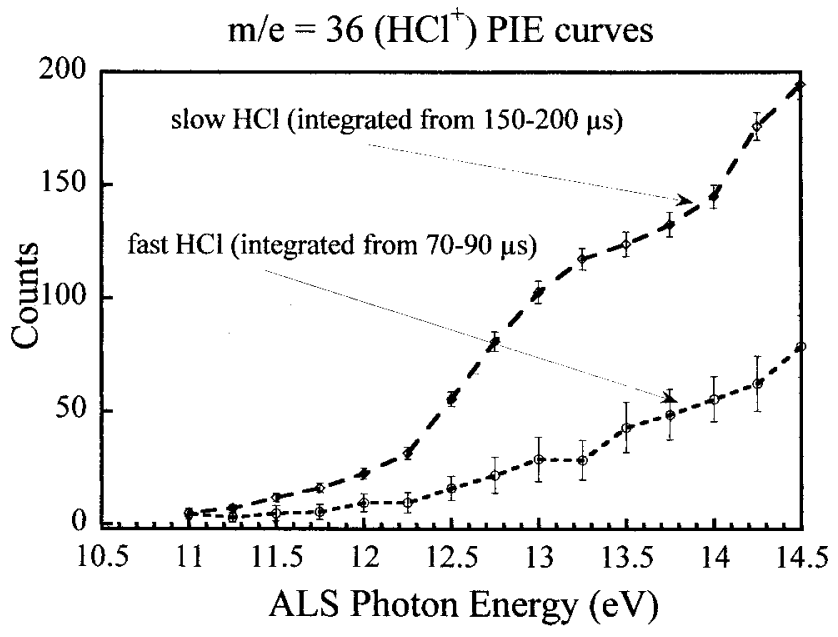

FIG. 8. Photoionization efficiency (PIE) curves obtained for $m / e=36$ (see Fig. 6). The signal was collected at a source-detector angle of $15^{\circ}$ and the undulator energy was stepped from 11.0 to $14.5 \mathrm{eV}$, with 40000 shots taken at each gap energy. The data is taken with a narrower energy linewidth and corrected for the undulator radiation flux. Data points are shown with error bars with straight-line extrapolations between each point to guide the eye. We integrated separately the PIE data in the two time windows seen in the $m / e=36$ spectra, taking care to eliminate overlap. Thus we integrated over 150-200 $\mu$ s for the low kinetic energy $\mathrm{HCl}$ elimination channel and over 70-90 $\mu$ s for the high kinetic energy $\mathrm{HCl}$ elimination channel. tional energy than the $\mathrm{HCl}$ elimination products at $193 \mathrm{~nm}$ from vinyl chloride and 2-chloropropene. ${ }^{16,17}$

As noted previously, the $m / e=40\left(\mathrm{C}_{3} \mathrm{H}_{4}^{+}\right)$TOF spectrum shown in Fig. 4 primarily consists of the $\mathrm{C}_{3} \mathrm{H}_{4}$ products from two sources. The portion of the signal fit in the shortdashed line is easily assigned to $\mathrm{C}_{3} \mathrm{H}_{4}$ fragments resulting from the $\mathrm{HCl}$ elimination channel of allyl chloride where increased kinetic energy is partitioned to the products formed. This fast signal from 74 to $\sim 90 \mu$ s was thus fit by momentum matching it to the high kinetic energy elimination channel seen at $m / e=36$ (Fig. 6). A second process, yielding most of the slower broad peak extending from $\sim 90$ to $\sim 300$ $\mu \mathrm{s}$, was fit by assuming it arises from secondary dissociation of the higher internal energy allyl radicals formed upon $\mathrm{C}-\mathrm{Cl}$ fission in the primary photolysis. As stated earlier, fragments with times of arrival of approximately $125 \mu \mathrm{s}$ and longer in the $m / e=40$ TOF spectrum are indeed well fit by the slow $P\left(E_{T}\right)$ used to fit the slow $\mathrm{Cl}$ signal. However, there is also signal in an intermediate portion of the $m / e=40$ spectrum that is not fit by either of the above distributions. This signal is hypothesized to be the stable co-fragments of the low kinetic energy $\mathrm{HCl}$ products. (Depending on the kinetic energy release in the $\mathrm{HCl}$ elimination reaction, $\mathrm{HCl}$ elimination can form either stable $\mathrm{C}_{3} \mathrm{H}_{4}$ or $\mathrm{C}_{3} \mathrm{H}_{4}$ which dissociates to $\mathrm{C}_{3} \mathrm{H}_{3}+\mathrm{H}$.)

Since the total $\mathrm{HCl}$ elimination $P\left(E_{T}\right)$ used to fit the data in Fig. 6 must be the sum of two individual $P\left(E_{T}\right)$ 's, one with stable co-fragments to the $\mathrm{HCl}$ and the other with unstable co-fragments to the $\mathrm{HCl}$ that appear at $m / e=39$, we were able to check the consistency of our above hypothesis by using the information given to us by the data observed at $m / e=39\left(\mathrm{C}_{3} \mathrm{H}_{3}^{+}\right.$, see Fig. 10). The $\mathrm{HCl}$ elimination reactions which do not produce stable $\mathrm{C}_{3} \mathrm{H}_{4}$ products observed in the $m / e=40$ spectra must partition enough internal energy to the $\mathrm{C}_{3} \mathrm{H}_{4}$ products to allow $\mathrm{H}$ atom loss, forming $\mathrm{H}$ + propargyl (detected at the parent ion mass of $m / e=39$ ). Therefore, to fit the slow-arriving signal in the $m / e=39$ spectra, we took the bimodal $P\left(E_{T}\right)$ in Fig. 7 (solid line) used to fit the $m / e=36\left(\mathrm{HCl}^{+}\right)$signal, subtracted out the distribution required to fit the $m / e=40\left(\mathrm{C}_{3} \mathrm{H}_{4}^{+}\right)$signal, and indeed the remaining $P\left(E_{T}\right)$, shown in the dotted-dashed line in Fig. 9, fits the slow TOF signal at $m / e=39$ well. All three $P\left(E_{T}\right)$ 's that we used to fit the $m / e=36$, the scaled $m / e=40$, and the resulting $m / e=39$ are shown together in Fig. 9. One can, from these, determine the fraction of the $\mathrm{C}_{3} \mathrm{H}_{4}$ product from the slow $\mathrm{HCl}$ channel that dissociates to mass 39 rather than remaining stable at mass 40 .

To determine the ionization curve for the secondary dissociation products of $\mathrm{HCl}$ co-fragments produced in the low kinetic energy $\mathrm{HCl}$ elimination channel, we chose to take the PIE curve for mass 39 and integrate over the time gate (126$200 \mu \mathrm{s})$ corresponding to the secondary mass 39 product from nascent $\mathrm{C}_{3} \mathrm{H}_{4}$ products. The PIE curve taken at $\mathrm{m} / \mathrm{e}$ $=39$ is shown in Fig. $11\left(\mathrm{C}_{3} \mathrm{H}_{3}^{+}\right.$, collected at $15^{\circ}$ for 40000 shots at each photoionization energy which was scanned from 7.50 to $11.50 \mathrm{eV}$ ). The literature IE for propargy $1^{18}$ is $8.67 \mathrm{eV}$; our observed ionization onset for the $m / e=39 \mathrm{sig}$ nal is also below $9 \mathrm{eV}$, at approximately $8.5 \mathrm{eV}$, confirming the likelihood that the signal between 100 and $200 \mu$ s flight 


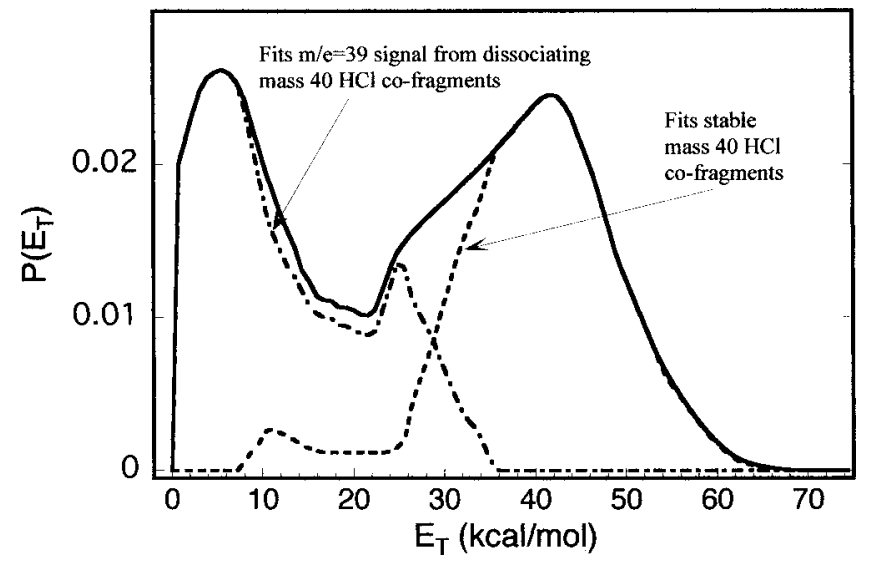

FIG. 9. Product translational energy distributions, $P\left(E_{T}\right)$, for $\mathrm{HCl}$ elimination in allyl chloride photolysed at $193 \mathrm{~nm}$, decomposing Fig. 7 into the stable and unstable components. Since the total $\mathrm{HCl}$ elimination $P\left(E_{T}\right)$ seen in Fig. 7 must be the sum of the individual $P\left(E_{T}\right)$ 's, we were able to check the consistency of our hypothesis that the intermediate portion of the $m / e$ $=40$ spectrum are stable co-fragments of the low kinetic energy $\mathrm{HCl}$ products. To fit the slow-arriving signal in the $m / e=39$ spectra (Fig. 10), we took the bimodal $P\left(E_{T}\right)$ in Fig. 4 used to fit the $m / e=36\left(\mathrm{HCl}^{+}\right)$signal (solid line), subtracted out the distribution required to fit the $m / e=40$ $\left(\mathrm{C}_{3} \mathrm{H}_{4}{ }^{+}\right)$signal (long-dashed line), and indeed the remaining $P\left(E_{T}\right)$, shown in dot-dashed line, fits the slow TOF signal at $m / e=39$ well.

time is propargyl radical from the secondary dissociation of $\mathrm{C}_{3} \mathrm{H}_{4}$ primary products from $\mathrm{HCl}$ elimination of allyl chloride. Indeed, since the endothermicity of the net reaction $\mathrm{H}_{2} \mathrm{C}=\mathrm{CHCH}_{2} \mathrm{Cl} \rightarrow \mathrm{HCl}+\mathrm{C}_{3} \mathrm{H}_{3}+\mathrm{H} \quad$ is $24.5 \mathrm{kcal} / \mathrm{mol}^{19}$ $+87.8 \mathrm{kcal} / \mathrm{mol}=112.3 \mathrm{kcal} / \mathrm{mol}$ (the photolysis provides $148 \mathrm{kcal} / \mathrm{mol}$ energy), even $\mathrm{HCl}$ elimination reactions that partition as much as $36 \mathrm{kcal} / \mathrm{mol}$ into product translation

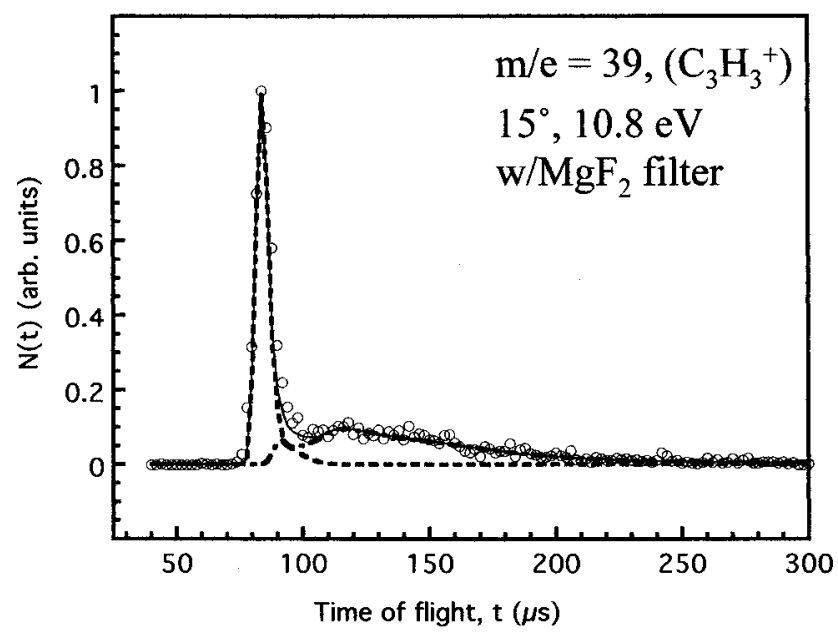

FIG. 10. Time of flight spectrum of the $m / e=39$ signal photoionized at 10.8 $\mathrm{eV}$ at a $15^{\circ}$ source-detector angle. The signal primarily consists of the $\mathrm{C}_{3} \mathrm{H}_{3}+$ products from two sources, propargyl produced from secondary dissociation of the nascent high internal energy $\mathrm{C}_{3} \mathrm{H}_{4}$ products [fit in dotteddashed line, with this dotted-dashed part of the total $\mathrm{HCl}$ elimination $P\left(E_{T}\right)$ shown in Fig. 11] which are produced from $\mathrm{HCl}$ elimination, and daughter ions of the allyl radical resulting from dissociative ionization of the stable allyl radicals from $\mathrm{C}-\mathrm{Cl}$ fission. There may well be some contribution to the fast peak from the dissociative ionization of stable mass 40 products from $\mathrm{HCl}$ elimination to the $\mathrm{C}_{3} \mathrm{H}_{3}+$ daughter ion, but that signal would have very similar TOF spectra as any fast signal from dissociative ionization of the mass 41 products to $m / e=39$ so cannot be independently identified.

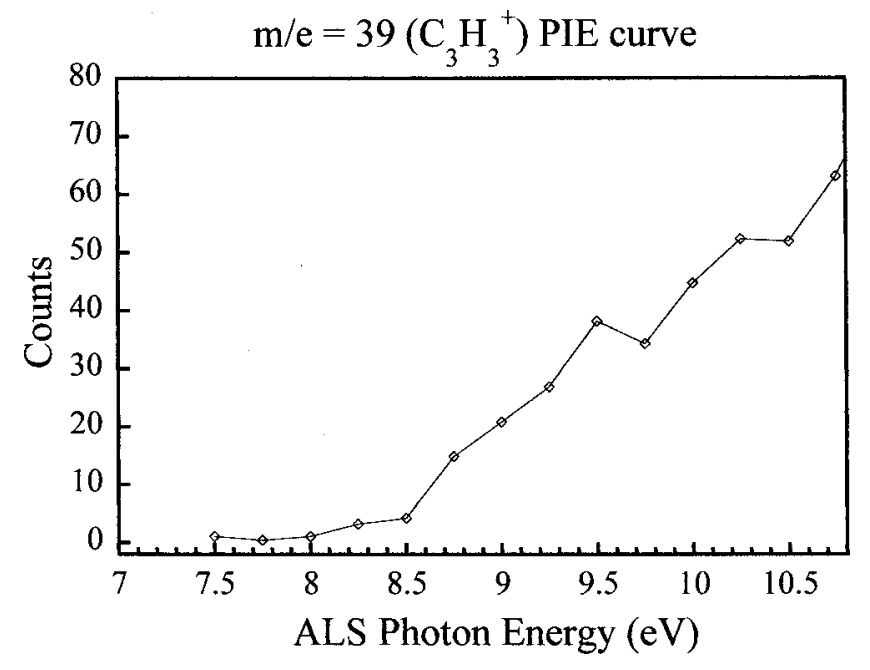

FIG. 11. Photoionization efficiency (PIE) curves obtained for mass 39 (see Fig. 10). We integrated over the time window corresponding to the arrival times of the slow secondary dissociation product from the unstable mass 40 $\mathrm{HCl}$ elimination product, 126-200 $\mu$ s. The signal was collected at a sourcedetector angle of $15^{\circ}$ and the undulator energy was stepped from $7.5 \mathrm{eV}$ to $11.5 \mathrm{eV}$. Points below $10.8 \mathrm{eV}$ were taken with $\mathrm{a} \mathrm{MgF}_{2}$ window in the photon beam; 40000 shots were taken at each gap energy. The literature IE for propargyl is $8.67 \mathrm{eV}$; our observed ionization onset for the $m / e=39$ signal is also below $9 \mathrm{eV}$, confirming the likelihood that the signal between 100 and $200 \mu$ s flight time is propargyl radical from the secondary dissociation of $\mathrm{C}_{3} \mathrm{H}_{4}$ primary products from $\mathrm{HCl}$ elimination of allyl chloride.

could form nascent $\mathrm{C}_{3} \mathrm{H}_{4}$ products with enough internal energy to dissociate to propargyl $+\mathrm{H}$. This closely corresponds to the onset of the dotted-dashed $P\left(E_{T}\right)$ seen in Fig. 9, our experimentally determined threshold for this secondary dissociation reaction. Of course, when the $\mathrm{HCl}$ carries away some vibrational energy one can find stable $\mathrm{C}_{3} \mathrm{H}_{4}$ products from $\mathrm{HCl}$ elimination events that release less than $36 \mathrm{kcal} /$ mol to product translation, and the stable $\mathrm{C}_{3} \mathrm{H}_{4}$ dashed line $P\left(E_{T}\right)$ in Fig. 9 does in fact extend to kinetic energies less than this $36 \mathrm{kcal} / \mathrm{mol}$ limit.

The remaining peak seen in the $m / e=39$ data, the signal at the fastest arrival times, is fit as daughter ions of the allyl radical (these fragments arriving at the fast times in the $m / e=39$ data have too much translational energy to be fragments produced in a secondary dissociation event). The mass $41 P\left(E_{T}\right)$ fits this portion of the $m / e=39$ spectra well. However, this may also include a contribution from dissociative ionization of vibrationally excited but stable allene from the fast $\mathrm{HCl}$ elimination channel. Both sources predict a sharp peak at similar arrival times. In our branching ratio determination presented in the next section, we assume that very little of the stable allene from $\mathrm{HCl}$ elimination undergoes dissociative ionization at $10.8 \mathrm{eV}$ photoionization energies.

Hence, we have two $\mathrm{HCl}$ elimination pathways producing fast and slow fragments. To try to distinguish between the possible reaction products (allene, propyne, or cyclopropene from a $\mathrm{C}_{3} \mathrm{H}_{4}$ biradical) for the higher kinetic energy $\mathrm{HCl}$ elimination channel, we took PIE data at $m / e=40$. The PIE curve of $m / e=40$ products shown in Fig. 5 in open squares, integrated over a 74-86 $\mu$ s time window, corresponds to the arrival times of the product momentum matched to the fast $\mathrm{HCl}$ fragment. We can see that the ion- 
ization onset is between 8 and $8.5 \mathrm{eV}$, quite a bit lower than the literature IE of either allene or propyne. In the work of Mueller et al. it was found that the PIE curve for propyne did not significantly redshift with increasing internal energy while that of allene did. This is consistent with the fact that the geometry of the allene ion differs significantly from that of the neutral allene. We therefore assign the $\mathrm{C}_{3} \mathrm{H}_{4}$ elimination products formed in the channel with high kinetic energy as vibrationally excited allene that is stable to further dissociation to propargyl $+\mathrm{H}$. The allene is significantly vibrationally excited; however, its $\mathrm{HCl}$ co-fragment shows only a modest redshift in its PIE curve as compared to that of the elimination product from either vinyl chloride or 2-chloropropene. We return to this in the discussion.

\section{Product channel branching}

We determine the branching ratio between the two $\mathrm{C}-\mathrm{Cl}$ bond fission channels of allyl chloride photolyzed with 193 $\mathrm{nm}$ light to be (high kinetic energy $\mathrm{C}-\mathrm{Cl}$ ): (low kinetic energy $\mathrm{C}-\mathrm{Cl})=97.1: 2.9$ by fitting the relative intensities of the $\mathrm{Cl}$ atom TOF spectrum in Fig. 2 (including corrections for kinetic factors, transit-time through the ionizer, etc). This branching ratio assumes that both the $\mathrm{C}-\mathrm{Cl}$ fission channels have the same anisotropy parameter, although our derived branching ratio is quite insensitive to this consideration as we are using unpolarized light to dissociate the molecule. Furthermore, since the high kinetic energy $\mathrm{C}-\mathrm{Cl}$ fission channel has a very small anisotropy parameter ${ }^{1}$ and the low kinetic energy $\mathrm{C}-\mathrm{Cl}$ channel results from a mechanism involving internal conversion, the angular distribution of both $\mathrm{C}-\mathrm{Cl}$ fission channels are near isotropic and thus the assumption of similar anisotropy parameters for both channels is well justified.

To estimate the $\mathrm{C}-\mathrm{Cl}$ fission versus $\mathrm{HCl}$ elimination product branching we need two additional assumptions. The first is that the mass 40 signal, which is momentum matched to the low kinetic energy $\mathrm{Cl}$ atoms, represents the full $2.9 \%$ of all $\mathrm{C}-\mathrm{Cl}$ bond fission events (all radicals produced in the slow $\mathrm{C}-\mathrm{Cl}$ bond fission channel are unstable); and, second, we assume that the photoproduct detection efficiency at 10.8 $\mathrm{eV}$ for the allene products from the secondary dissociation of allyl radical is the same as the detection efficiency for the primary stable allene product from $\mathrm{HCl}$ elimination. Then accounting for kinematic factors in the 3D scattering, the relative intensities in Fig. 4 determine that the ratio of surviving allene from $\mathrm{HCl}$ elimination to secondary allene from $\mathrm{C}-\mathrm{Cl}$ fission events that produce unstable allyl radical is 0.892:0.108 (again assuming no anisotropy difference). The fraction of mass 40 products from $\mathrm{HCl}$ elimination that are stable to secondary dissociation is $0.523(52.3 \%)$ and the fraction of allyl radical products from $\mathrm{C}-\mathrm{Cl}$ fission that undergo secondary dissociation to mass $40+\mathrm{H}$ is 0.029 (2.9\%), so the resulting ratio of total $\mathrm{HCl}$ elimination: total $\mathrm{C}-\mathrm{Cl}$ fission is determined to be 0.314:0.686. However, we should note that there is recent evidence ${ }^{10}$ that the allyl radical may be stable to secondary dissociation at internal energies higher than the $60 \mathrm{kcal} / \mathrm{mol}$ barrier calculated by Davis et al. Should this be the case, we will have overestimated the amount of $\mathrm{C}-\mathrm{Cl}$ fission contributing to the signal in the mass
40 spectrum. This would cause an underestimation of the low kinetic energy $\mathrm{HCl}$ products remaining stable to dissociation.

To determine the branching between the high kinetic energy $\mathrm{HCl}$ elimination channel and the low kinetic energy $\mathrm{HCl}$ elimination channel, we can use the normalized and weighted $P\left(E_{T}\right)$ 's in Fig. 7 and find the branching to be $0.635: 0.365$. Again, this branching is dependent on our assumption that all high internal energy allyl radicals undergo secondary dissociation.

To summarize, the branching ratios obtained in this work for [all $\mathrm{HCl}$ : : fast $\mathrm{HCl}$ ] : [slow $\mathrm{HCl}$ ] : [fast $\mathrm{C}-\mathrm{Cl}$ ] : [slow $\mathrm{C}-\mathrm{Cl}]:$ [all $\mathrm{C}-\mathrm{Cl}$ ] is 0.458:0.291:0.167:0.971:0.029:1.000.

\section{DISCUSSION}

\section{$\mathrm{C}-\mathrm{Cl}$ bond fission and secondary reactions of the nascent allyl radical}

$\mathrm{C}-\mathrm{Cl}$ bond fission in allyl chloride requires 71.20 $\mathrm{kcal} / \mathrm{mol},{ }^{20}$ leaving $76.8 \mathrm{kcal} / \mathrm{mol}$ available after excitation with $193 \mathrm{~nm}$ light to be partitioned into internal and translational modes of the nascent products. (We neglect the $<2$ $\mathrm{kcal} / \mathrm{mol}$ of internal energy in the parent molecule.) Reasoning from the barrier heights calculated by Davis et al., nascent allyl radical formed with greater than about $60 \mathrm{kcal} /$ mol internal energy in the ground electronic state can either lose a hydrogen to form allene $+\mathrm{H}$ or, with slightly higher internal energy, isomerize to 2-propenyl radical with subsequent loss of hydrogen atom to produce either propyne or allene. A minor channel forming methyl radical + acetylene is also energetically possible but mechanistically difficult and was looked for (but not conclusively identified) in the experiments presented here. This latter channel was described in the work of Stranges et al. but not identified in the work on the UV photodissociation of the allyl radical performed by Chen and co-workers. ${ }^{2,7,8}$

While two $\mathrm{C}-\mathrm{Cl}$ fission channels were seen in the similar molecules vinyl chloride and 2-chloropropene, only one $\mathrm{C}-\mathrm{Cl}$ bond fission channel was formerly identified for the $193 \mathrm{~nm}$ photodissociation of allyl chloride. Looking first at this previously seen high kinetic energy channel, we see that the $P\left(E_{T}\right)$ describing the translational energy release for this channel is consistent in average kinetic energy and breadth with that seen by Myers et al. ${ }^{1}$ This $\mathrm{C}-\mathrm{Cl}$ bond dissociation channel is assigned for allyl chloride, as it is for vinyl chloride and 2-chloropropene, as a predissociation of a dominantly $\pi \pi^{*}$ state by a nearby $n \sigma^{*}$ state (or a $\pi \sigma^{*}$ state at nonplanar geometries). Thus we expect this channel to partition a large energy release into product recoil due to the exit barriers for excited state dissociation in all three cases. However, the $P\left(E_{T}\right)$ 's describing the high kinetic energy $\mathrm{C}-\mathrm{Cl}$ bond fission channel in both vinyl chloride and 2-chloropropene peak at considerably lower energy $(\sim 20$ $\mathrm{kcal} / \mathrm{mol}$ versus the $\sim 40 \mathrm{kcal} / \mathrm{mol}$ for allyl chloride $\mathrm{C}-\mathrm{Cl}$ fission). As a possible explanation, we point out that in the Franck-Condon region for the excitation of allyl chloride, there is significant admixture of $\sigma^{*}{ }_{\mathrm{C}-\mathrm{Cl}}$ character in the $\pi \pi^{*}$ state. $^{1,21}$ This yields a more repulsive surface even in the Franck-Condon region and thus might account for the additional energy released to product recoil in the $\mathrm{C}-\mathrm{Cl}$ bond 
fission channel of allyl chloride over that seen in vinyl chloride and 2-chloropropene.

Turning next to examine the low kinetic energy $\mathrm{C}-\mathrm{Cl}$ bond fission channel, we first note that support for an internal conversion mechanism for the low kinetic energy channel in 2-chloropropene is quite strong. ${ }^{17}$ The experimentally determined $P\left(E_{T}\right)$ for this channel in 2-chloropropene was very well predicted by RRKM theory assuming no exit barrier. (C-Cl fission in ground state 2-chloropropene is endothermic by $93.4 \mathrm{kcal} / \mathrm{mol}$ and is not expected to have a significant exit barrier.) While we postulate a similar mechanism involving internal conversion and subsequent ground state dissociation to explain the low kinetic energy channel in allyl chloride, we would not expect the translational energy distribution for this channel to be well represented by an RRKM $P\left(E_{T}\right)$ since there is expected to be a substantial exit barrier to $\mathrm{C}-\mathrm{Cl}$ bond fission in ground state allyl chloride. (There are currently no studies of the $\mathrm{C}-\mathrm{Cl}$ reaction coordinate for ground state allyl chloride.) The ground state $\mathrm{C}-\mathrm{Cl}$ bond fission pathway of allyl chloride is not well described by a simple bond fission model; significant resonance stabilization of the allyl radical produced would be expected due to delocalization of the $\pi$-bonding electron density across both carbon-carbon bonds. As evidence of this, the endothermicity of $\mathrm{C}-\mathrm{Cl}$ fission in allyl chloride is only $71.2 \mathrm{kcal} / \mathrm{mol}$, whereas a typical $\mathrm{C}-\mathrm{Cl}$ single bond dissociation enthalpy is $\geqslant 84 \mathrm{kcal} / \mathrm{mol}$. And indeed, the product kinetic energy distribution for the low kinetic energy $\mathrm{C}-\mathrm{Cl}$ bond fission channel, while slow, is not peaked at $0 \mathrm{kcal} / \mathrm{mol}$, showing that a simple RRKM-calculated $P\left(E_{T}\right)$ would not well represent this reaction. Furthermore, in comparison with the product channel branching in the $193 \mathrm{~nm}$ photodissociation of 2-chloropropene, this second reaction pathway resulting from allyl chloride photolyzed at $193 \mathrm{~nm}$ comprises a much smaller percentage of all $\mathrm{C}-\mathrm{Cl}$ bond fission events $(\sim 3 \%$ in allyl chloride versus $23 \%$ in 2-chloropropene). The more repulsive nature of the allyl chloride $\pi \pi^{*} / n \sigma^{*}$ potential energy surface in the Franck-Condon region might be an explanation for this smaller branching to the low kinetic energy channel: the repulsive kick provided by the mixing of $\sigma^{*}{ }_{\mathrm{C}-\mathrm{Cl}}$ character quickly stretches the $\mathrm{C}-\mathrm{Cl}$ bond, leaving less time in the region of the PES that might be subject to undergoing internal conversion to the ground state.

Of those $3 \%$ of $\mathrm{C}-\mathrm{Cl}$ bond fission events that produce high internal energy allyl radicals, nearly $100 \%$ have enough internal energy to unimolecularly dissociate (if the $60 \mathrm{kcal} /$ mol barrier to dissociation to allene $+\mathrm{H}$ shown in Fig. 1 is correct). After photodissociation with $193 \mathrm{~nm}$ light, ground state $\mathrm{C}_{3} \mathrm{H}_{5}$ products from the low kinetic energy $\mathrm{C}-\mathrm{Cl}$ bond fission channel of allyl chloride have $0-16 \mathrm{kcal} / \mathrm{mol}$ internal energy above this lowest reaction barrier calculated ${ }^{4}$ for the allyl radical. Within this range of available internal energies, the allyl radical can in principle either undergo secondary dissociation to give allene $+\mathrm{H}$ directly or undergo isomerization to the 2-propenyl radical, which then dissociates to give allene $+\mathrm{H}$ or propyne $+\mathrm{H}$ in a ratio determined by the internal energy available as found by Mueller et al. ${ }^{17}$ One other possible secondary dissociation process of the allyl radical produced from photodissociation of allyl chloride would yield methyl+acetylene after $\mathrm{C}-\mathrm{C}$ bond fission, which might occur either subsequently to isomerization to the 1-propenyl radical or, as proposed by Stranges et al., ${ }^{2}$ via a tight four-membered cyclic transition state that gives methyl+acetylene directly from the allyl radical. The small branching to the primary $\mathrm{C}-\mathrm{Cl}$ bond fission channel in allyl chloride producing unstable allyl radicals prevents a good determination of the branching to the different secondary reaction channels for allyl radical in our experiments, but the dissociation to allene $+\mathrm{H}$ clearly dominates over the other possible secondary reaction channels at the energies used in our experiments.

Our findings with respect to the $\mathrm{C}-\mathrm{H}$ fission secondary products of the allyl radical are in qualitative agreement with those of Chen and co-workers; however, Chen's work was at a much higher internal energy where the pathways opened up by isomerization to 2-propenyl are expected to compete more effectively with $\mathrm{C}-\mathrm{H}$ bond fission from the allyl radical. They found that the branching ratio for formation of allene directly from allyl:isomerization from allyl to 2-propenyl with subsequent hydrogen loss to be between 2:1 and $3: 1{ }^{7,8}$ In our experiments, where the maximum internal energy of the allyl radical is about $77 \mathrm{kcal} / \mathrm{mol}$ and most of the allyl radicals are produced with much lower internal energy, one does not expect isomerization to the 2-propenyl radical to compete effectively with $\mathrm{C}-\mathrm{H}$ bond fission from the allyl isomer to form $\mathrm{H}+$ allene (RRKM calculations, neglecting centrifugal effects, ${ }^{10}$ with $77 \mathrm{kcal} / \mathrm{mol}$ internal energy of the allyl radical gave $k_{\mathrm{H}+\text { allene }} / k_{\text {isom } \rightarrow 2 \text {-propenyl }}$ $=16: 1$ ). Indeed, the comparison of our 10.0 and $10.8 \mathrm{eV}$ spectra evidence no significant branching to $\mathrm{H}+$ propyne, a channel that would occur with a good quantum yield if a significant fraction of the allyl radical isomerizes to 2-propenyl. (Our prior work on the unimolecular dissociation of 2-propenyl radicals shows that the branching to $\mathrm{H}$ + propyne dominates the branching to $\mathrm{H}+$ allene even at high internal energies. This occurs because the A factor for the $\mathrm{H}+$ propyne channel is much more favorable and the barrier heights for the two channels are very similar; the barrier to $\mathrm{H}+$ propyne is about $1 \mathrm{kcal} / \mathrm{mol}$ less than the barrier to $\mathrm{H}+$ allene, in agreement with the findings of Davis et al.)

This work does not shed light on a possible $\mathrm{C}-\mathrm{C}$ bond fission channel of the allyl radical. Chen and co-workers also did not identify a $\mathrm{C}-\mathrm{C}$ bond fission channel from the allyl radical. In the work of Stranges et al., a $\mathrm{C}-\mathrm{C}$ bond fission channel of the allyl radical was identified after excitation at $248 \mathrm{~nm}$ followed by internal conversion to the ground state. However, Stranges et al. did not detect this $\mathrm{C}-\mathrm{C}$ bond fission channel of allyl radical after excitation with $351 \mathrm{~nm}(3.53$ $\mathrm{eV}$ ) light, which is still higher than the energies available for the allyl radical in our experiment, and they postulated an internal conversion followed by a ground state dissociation mechanism after excitation at this wavelength as well. In the work of Davis et al. one can identify a mechanism for $\mathrm{C}-\mathrm{C}$ fission which involves isomerization through the 1-propenyl radical. This mechanism may be more viable than the tight four-centered transition state of the allyl radical leading directly to methyl+acetylene proposed by Stranges et al. Our 
preliminary studies of the direct dissociation channels of the 1-propenyl radical show that there is likely significant branching to the $\mathrm{C}-\mathrm{C}$ bond fission channel. ${ }^{22}$

Since both $\mathrm{C}-\mathrm{Cl}$ fission channels yield small signal over the translational energy range corresponding to $\sim 16-20$ $\mathrm{kcal} / \mathrm{mol}$, we cannot comment on an exact barrier height for the allyl $\rightarrow \mathrm{H}+$ allene dissociation; this is investigated in more detail in the work of Szpunar et al. ${ }^{10}$ However, it is evident from our experiments that allyl radicals are stable to dissociation with internal energies up to $56.8 \mathrm{kcal} / \mathrm{mol}$ and at internal energies above that do not give significant branching to propyne $+\mathrm{H}$. Stranges et al. interpreted their results using a much lower barrier to isomerization of the allyl radical than the $63.8 \mathrm{kcal} / \mathrm{mol}$ isomerization barrier calculated since by Davis et al. (Stranges et al. adopted the value of 48.6 $\mathrm{kcal} / \mathrm{mol}^{2}{ }^{2}$ ) Our work supports the findings of Davis et al. since our stable allyl radicals produced from the high kinetic energy $\mathrm{C}-\mathrm{Cl}$ bond fission channel of allyl chloride have a range of internal energies that span 16 to $56.8 \mathrm{kcal} / \mathrm{mol}$ (plus parent internal energy) and the allyl radicals produced from the low translational energy $\mathrm{C}-\mathrm{Cl}$ fission channel yield primarily allene; a fraction of these should isomerize if the value for the barrier height used by Stranges et al. was correct. Indeed, as was mentioned previously, formation of 2-propenyl radicals from the allyl radical should increase product branching probability to the propyne $+\mathrm{H}$ channel, which becomes energetically allowed at $\mathrm{C}_{3} \mathrm{H}_{5}$ internal energies of $57.5 \mathrm{kcal} / \mathrm{mol}$ above the zero point level of allyl. Our experiment shows that the branching to propyne $+\mathrm{H}$ is not significant, so showing that very few of the nascent allyl radicals isomerize to 2-propenyl. Rather, direct dissociation to $\mathrm{H}+$ allene is the preferred pathway. Furthermore, as mentioned previously, RRKM calculations using the parameters given in the paper by Davis et al., with an internal energy of the allyl radical of $77 \mathrm{kcal} / \mathrm{mol}$, gives the ratio of rates of dissociating allyl: isomerizing allyl of $k_{\mathrm{H}+\text { allene }} / k_{\text {isom } \rightarrow 2 \text {-propenyl }}$ $=16: 1$. (Note, though, that centrifugal effects are not included in this calculation and they can be important in the dissociation of allyl to allene $+\mathrm{H}^{10}$ ) One explanation for the insensitivity of the Stranges et al. data to the different predictions of the isomerization barrier height is the higher energies used by Stranges et al.; they examined the photodissociation of the allyl radical after excitation with $248 \mathrm{~nm}$ $(\sim 5 \mathrm{eV})$ and at $351 \mathrm{~nm}(3.53 \mathrm{eV})$ where one is more sensitive to the ratio of A-factors between the isomerization and $\mathrm{C}-\mathrm{H}$ bond fission channels than their relative barrier heights. In contrast, our experiments are sensitive to the whole range of internal energies up to $3 \mathrm{eV}$.

Thus, the dominant secondary pathway of the allyl radical produced from the low kinetic energy $\mathrm{C}-\mathrm{Cl}$ fission channel of allyl chloride is the direct formation of allene $+\mathrm{H}$ by hot ground state allyl radicals. A second channel, isomerization to the 2-propenyl radical followed by subsequent hydrogen loss, allows formation of both allene $+\mathrm{H}$ and propyne $+\mathrm{H}$, but this is at most a minor channel at the energies used in our experiments; the $m / e=40$ signal due to allyl $\mathrm{C}-\mathrm{H}$ bond fission products does not change when tuning the photoionization energy from 10.8 to $10.0 \mathrm{eV}$ as we would expect if propyne $+\mathrm{H}$ was quantitatively formed. Finally, a third channel, production of methyl radical+acetylene, may be a minor reaction pathway of the allyl radical but was not positively identified in this work.

\section{$\mathrm{HCl}$ elimination and secondary dissociation of the nascent $\mathrm{C}_{3} \mathrm{H}_{4}$ products}

There are two distinct $\mathrm{HCl}$ elimination product kinetic energy distributions seen for the $\mathrm{HCl}$ elimination in allyl chloride. This is a marked difference from what was seen in vinyl chloride and 2-chloropropene, where only a single broad kinetic energy distribution was seen for $\mathrm{HCl}$ elimination. While mechanisms involving internal conversion to the ground state followed by elimination of $\mathrm{HCl}$ have been proposed for the UV photo-reactions of vinyl chloride and 2-chloropropene, temperature studies by Myers et al., as mentioned in the Introduction of this article, suggest that at least one of the two elimination pathways, in particular the high kinetic energy channel, might occur on an excited state surface. $^{1}$

Examining this $\mathrm{HCl}$ elimination channel in allyl chloride which produces mass 40 fragments with a large energy release into product recoil, we note several interesting things. First, as we would expect, the $\mathrm{HCl}$ momentum matched to these high translational energy mass 40 fragments is colder than the $\mathrm{HCl}$ produced in the low kinetic energy channel (see Fig. 8), and the $P\left(E_{T}\right)$ for the fast products peaks at just over $40 \mathrm{kcal} / \mathrm{mol}$. The large recoil kinetic energy partitioned to products of this reaction suggests that the reaction may be due to an excited state mechanism. Second, the experimentally determined $P\left(E_{T}\right)$ for this channel extends from 15 to $65 \mathrm{kcal} / \mathrm{mol}$ and is not symmetric in shape, so more than one mechanism may contribute to this fast $\mathrm{HCl}$ elimination channel. Indeed, near the shoulder around $\sim 30 \mathrm{kcal} / \mathrm{mol}$ in the fast $\mathrm{HCl}$ elimination $P\left(E_{T}\right)$ (Fig. 7), a significant fraction of the $\mathrm{C}_{3} \mathrm{H}_{4}$ co-fragments of the fast $\mathrm{HCl}$ products are formed with enough internal energy to undergo secondary dissociation to mass 39 (Fig. 10), as do most of the products of the low kinetic energy $\mathrm{HCl}$ elimination mechanism. Mechanism (1) suggested by Myers et al., formation of allene $+\mathrm{HCl}$ directly (rather than through a biradical intermediate), has an energetic cost of only $24.5 \mathrm{kcal} / \mathrm{mol}$. Our work indicates that we form primarily vibrationally excited allene via an excited state mechanism. Some of the nascent $\mathrm{C}_{3} \mathrm{H}_{4}$ products formed with less than $\sim 36 \mathrm{kcal} / \mathrm{mol}$ translational energy then undergo secondary dissociation to propargyl $+\mathrm{H}$.

Next we look at the low kinetic energy $\mathrm{HCl}$ elimination channel from allyl chloride. In doing so, comparison with similar molecules proves valuable. Examining previous experimental work on vinyl chloride, we find that the proposed pathway for the $\mathrm{HCl}$ elimination is a ground state mechanism following internal conversion. The dominant mechanism for $\mathrm{HCl}$ elimination in vinyl chloride was suggested to involve a 1,1-elimination (via a three-center transition state, also termed $\alpha, \alpha$-elimination) with synchronous isomerization to acetylene. The synchronous isomerization mechanism was included to rationalize the fact that while $a b$ initio results ${ }^{23}$ identified the 1,1-elimination as the lower barrier channel, the exit barrier upon 1,1-elimination is too small $(\sim 3 \mathrm{kcal} /$ 
mol) to account for the high kinetic energy release observed for $\mathrm{HCl}$ elimination in vinyl chloride by Blank et al. ${ }^{16} \mathrm{Y}$. P. Lee and co-workers ${ }^{24}$ investigated the vibrational and rotational emission spectrum of the $\mathrm{HCl}$ elimination from 193 $\mathrm{nm}$ photolysis of vinyl chloride and saw a bimodal distribution. They concluded that the high and low $J$ components correspond to $\mathrm{HCl}(\nu, J)$ produced from both three-and fourcentered elimination channels, respectively, with a branching ratio of 0.81:0.19. Gordon et al. ${ }^{12,13}$ studied the ultraviolet photodissociation dynamics of $d_{1}$-vinyl chloride, and also found that the three-centered elimination mechanism dominated over the four-centered (1,2-elimination, also termed an $\alpha, \beta$-elimination) mechanism with a branching ratio of threecentered:four-centered of 3:1. The work of Riehl et al., ${ }^{23}$ who performed an ab initio study on the unimolecular dissociation reactions of vinyl chloride, supported the dominance of the 1,1-elimination reaction pathway, since the calculations showed that the 1,2-elimination mechanism had a higher barrier than 1,1-elimination. However, the exit barrier for the three-center reaction was only $2.5 \mathrm{kcal} / \mathrm{mol}$, and so was inconsistent with the high kinetic energy of the $\mathrm{HCl}$ products observed (the distribution fit to this channel by Blank et al. extended to $70 \mathrm{kcal} / \mathrm{mol}$ and had an average value of $18 \mathrm{kcal} / \mathrm{mol}$ ). This is indeed why Blank and coworkers inferred that a synchronous isomerization of the nascent singlet vinylidene to acetylene must occur during the $\alpha, \alpha$-elimination process, providing a repulsive interaction that could explain the large energy release in product recoil. Both a 1,1-and 1,2-elimination mechanism could possibly occur for the photo-induced $\mathrm{HCl}$ elimination in allyl chloride.

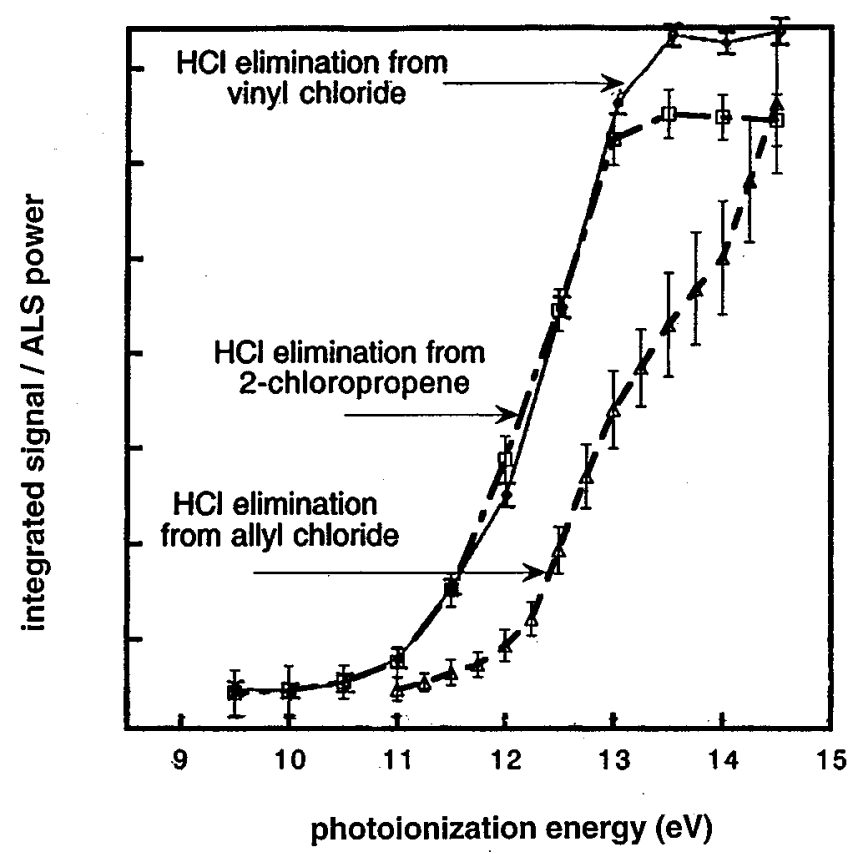

FIG. 12. A comparison of $\mathrm{HCl} \mathrm{PIE}$ curves from vinyl chloride, 2-chloropropene, and allyl chloride. Signal intensities have been scaled to make a comparison between $\mathrm{HCl}$ produced from the three molecules more easily seen. $\mathrm{HCl}$ produced in the low kinetic energy channel of allyl chloride, while redshifted from room temperature $\mathrm{HCl}$, is significantly colder vibrationally than the $\mathrm{HCl}$ formed from vinyl chloride or the four-centered elimination processes of 2-chloropropene. Figures reprinted with permission.

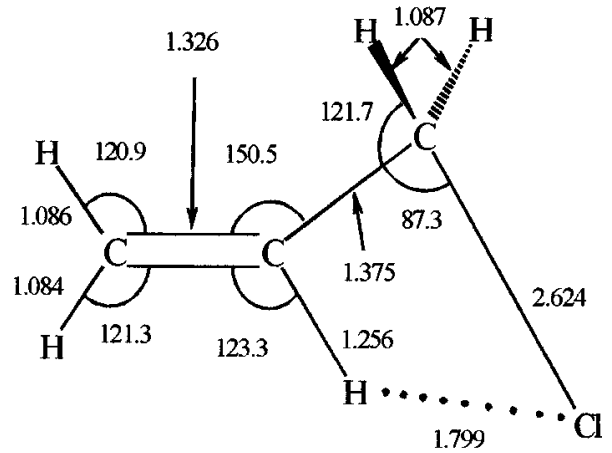

FIG. 13. The transition state structure for a possible four-centered $\mathrm{HCl}$ elimination from allyl chloride, calculated at the MP2 level of theory with a 6-31G* basis set.

Another valuable comparison is offered by the work of Mueller et al. which examined the UV photodynamics of 2-chloropropene excited at $193 \mathrm{~nm} .{ }^{17}$ The $\mathrm{HCl}$ elimination process in 2-chloropropene must be a 1,2-elimination mechanism (since 2-chloropropene has a methyl group rather than a hydrogen on the $\mathrm{C}-\mathrm{Cl}$ carbon) and the experimentally determined $P\left(E_{T}\right)$ for this channel as well as the measured $\mathrm{HCl}$ $\mathrm{PIE}$ curves for $\mathrm{HCl}$ elimination in 2-chloropropene are quite similar to those of vinyl chloride. Mueller et al. point out that while a second 1,2-elimination mechanism with no ana$\log$ in vinyl chloride likely also contributes to the $\mathrm{HCl}$ elimination process in 2-chloropropene, evidence supports that the dominant mechanism in 2-chloropropene is production of $\mathrm{HCl}+$ propyne via a 1,2-elimination mechanism that is also possible in vinyl chloride. Interestingly enough, the PIE curves of the $\mathrm{HCl}$ products from the elimination reactions of both 2-chloropropene and vinyl chloride are quite similar (see Fig. 12). As will be discussed, this has implications for a possible $\mathrm{HCl}$ elimination mechanism in allyl chloride.

Finally, an important comparison is available from the new molecular beam studies of Lin et al. ${ }^{25}$ on the $157 \mathrm{~nm}$ photodissociation of methyl chloride. The $\mathrm{CH}_{3} \mathrm{Cl}$ photodissociation to form $\mathrm{HCl}+\mathrm{CH}_{2}$ yields a bimodal distribution similar to that seen in our experiments on allyl chloride but in contrast to the single distribution seen in the dissociation of both vinyl chloride and 2-chloropropene. This suggests that a three-centered elimination mechanism, the only mechanism available for the elimination of $\mathrm{HCl}$ from methyl chloride, could indeed be a possible process occurring in allyl chloride.

Turning back to $\mathrm{HCl}$ elimination in allyl chloride, we first note that a comparison of the $\mathrm{HCl}$ PIE curve for the low kinetic energy $\mathrm{HCl}$ elimination channel in allyl chloride to that in 2-chloropropene (see Fig. 12) shows it to be inconsistent with a Franck-Condon model for the vibrational population distribution of the $\mathrm{HCl}$ if it is formed via the four-centered (1,2-elimination) transition state arrived at in recent $a b$ initio calculations (see Fig. 13). ${ }^{26}$ The $\mathrm{H}-\mathrm{Cl}$ bond length at the four-centered elimination transition state calculated is $1.799 \AA$, which is remarkably similar to the $\mathrm{H}-\mathrm{Cl}$ distances calculated for both of the four-centered elimination mechanisms in 2-chloropropene $(1.8 \AA) .{ }^{27}$ Based on a simple yet usually accurate model of increased vibrational energy 
correlating with increased bond length in the transition state, we would expect to see similarly redshifted HCl PIE curves in the elimination reactions of both molecules if both proceed through a four-center elimination mechanism. Clearly the comparison of the two PIE curves in Fig. 12 shows that $\mathrm{HCl}$ elimination in allyl chloride produces more vibrationally cold $\mathrm{HCl}$ and $\mathrm{HCl}$ elimination from 2-chloropropene. Based on the reasoning above, the $\mathrm{HCl}$ elimination in allyl chloride is unlikely to be a four-centered mechanism, which is consistent with the $P\left(E_{T}\right)$ comparison with the methyl chloride $\mathrm{HCl}$ elimination in the previous paragraph. The comparison of the PIE curve for the $\mathrm{HCl}$ elimination from 2-chloropropene to that from vinyl chloride is also at first surprising given that the elimination of $\mathrm{HCl}$ from vinyl chloride is believed to be dominated by a three-centered mechanism. The PIE curve of the $\mathrm{HCl}$ product from 2-chloropropene, which does not have a three-centered mechanism, is, while different from that in allyl chloride, similar to that from vinyl chloride photodissociation. However, the recent work by Lin et al. on vinyl chloride ${ }^{24}$ shows similar vibrational distributions for both the three and four-centered elimination processes in vinyl chloride. The similarity of the PIE curve of the $\mathrm{HCl}$ product from 2-chloropropene to that from vinyl chloride is thus consistent with Lin et al.'s work.

Our data on allyl chloride showed that the $\mathrm{HCl}$ produced in the low kinetic energy channel of allyl chloride, while redshifted from that formed in the high kinetic energy channel, is significantly colder vibrationally than the $\mathrm{HCl}$ formed from the four-centered elimination processes of 2-chloropropene and the three- and four-centered elimination processes in vinyl chloride. While a three-centered elimination transition state for the allyl chloride elimination reaction was not yet characterized in the preliminary calculations, such a mechanism would reasonably explain the cold $\mathrm{HCl}$ products formed (as compared to those from 2-chloropropene and vinyl chloride). Following a threecentered elimination mechanism, either synchronous isomerization to allene from the $\mathrm{H}_{2} \mathrm{C}=\mathrm{CHCH}$ : formed or secondary dissociation of the evolving radical to form propargyl $+\mathrm{H}$ could occur. We note here that the low kinetic energy channel produces mass 40 products of which only a small portion are stable to secondary dissociation. Thus, ab initio calculations on this possible three-centered $\mathrm{HCl}$ elimination transition state in allyl chloride would provide valuable information to help ascertain the potential contribution of three and four-centered elimination processes upon internal conversion to the ground state in allyl chloride. In addition, the $a b$ initio results of Stephenson ${ }^{26}$ give good RRKM parameters for a possible four-centered $\mathrm{HCl}$ elimination process. Thus, if one wanted to test if either $\mathrm{HCl}$ elimination channel occurred via internal conversion to the ground electronic state, one could calculate the ratio of that rate constant to the RRKM rate constant for $\mathrm{C}-\mathrm{Cl}$ fission and compare it to compare our experimentally observed $\mathrm{HCl}$-elimination: $\mathrm{C}-\mathrm{Cl}$ fission channel branching ratio for each $\mathrm{HCl}$ elimination channel. We look forward to accurate calculations of the $\mathrm{C}-\mathrm{Cl}$ fission transition state parameters being pursued in other groups to allow this comparison.

\section{ACKNOWLEDGMENTS}

This work was supported by the Division of Chemical Sciences, Office of Basic Energy Sciences, Office of Energy Research, U.S. Department of Energy, under Grant No. DEFG02-92ER14305 (L.J.B.). The ALS is supported by the Materials Sciences Division of the DOE under Contract No. DE-AC03-76SF00098. The authors gratefully acknowledge Paul M. Regan for taking $m / e=40$ spectra as well as for looking for a $\mathrm{C}-\mathrm{C}$ bond fission channel of the allyl radical. T. Baer is acknowledged for his support of the work at the ALS. Summer salary for T.A.S. was provided by an ROA supplement to NSF CHE 961-9376. T.A.S is grateful to Swarthmore College for sabbatical leave support.

${ }^{1}$ T. L. Meyers, D. C. Kitchen, B. Hu, and L. J. Butler, J. Chem. Phys. 104, 5446 (1996); erratum 105, 2948 (1996).

${ }^{2}$ D. Stranges, M. Stemmler, X. Yang, J. D. Chesko, A. G. Suits, and Y. T. Lee, J. Chem. Phys. 109, 5372 (1998).

${ }^{3}$ V. B. Ondruschka, U. Ziegler, and G. Zimmermann, Z. Phys. Chem. (Leipzig) 267, 1127 (1986).

${ }^{4}$ S. G. Davis, C. K. Law, and H. Wang, J. Phys. Chem. A 103, 5889 (1999).

${ }^{5}$ W. Tsang, Int. J. Chem. Kinet. 10, 1119 (1978).

${ }^{6}$ See, for example, K. M. Leung and R. P. Lindstedt, Combust. Flame 102, 129 (1995); M. Weissman and S. W. Benson, Prog. Energy Combust. Sci. 15, 273 (1989).

${ }^{7}$ H.-J. Deyerl, I. Fischer, and P. Chen, J. Chem. Phys. 110, 1450 (1999).

${ }^{8}$ H.-J. Deyerl, T. Gilbert, I. Fischer, and P. Chen, J. Chem. Phys. 107, 3329 (1997).

${ }^{9}$ X. Yang, J. Lin, Y. T. Lee, D. A. Blank, A. G. Suits, and A. M. Wodtke, Rev. Sci. Instrum. 68, 3317 (1997).

${ }^{10}$ D. E. Szpunar, M. L. Morton, F. Qi, P. M. Regan, and L. J. Butler, manuscript in preparation.

${ }^{11}$ See EPAPS Document No. E-JCPSA6-116-001207 for data and fits at second angles for confirmation of $P\left(E_{T}\right)$. This document may be retrieved via the EPAPS homepage (http.//www.aip.org/pubservs/epaps.html) or from ftp.aip.org in the directory /epaps/. See the EPAPS homepage for more information.

${ }^{12}$ Y. Huang, Y. Yang, G. He, S. Hashimoto, and R. J. Gordon, J. Chem. Phys. 99, 2752 (1993).

${ }^{13}$ Y. Huang, Y. Yang, G. He, S. Hashimoto, and R. J. Gordon, J. Chem. Phys. 103, 5476 (1995).

${ }^{14}$ K. Tonokura, L. B. Daniels, T. Suzuki, and K. Yamashita, J. Phys. Chem. 101, 7754 (1997).

${ }^{15}$ M. Umemoto, K. Seki, H. Shinohara, U. Nagashima, N. Nishi, M. Kinoshita, and R. Shimada, J. Chem. Phys. 83, 1657 (1985).

${ }^{16}$ D. A. Blank, W. Sun, A. G. Suits, Y. T. Lee, S. W. North, and G. E. Hall, J. Chem. Phys. 108, 5414 (1998).

${ }^{17}$ J. A. Mueller, B. F. Parsons, L. J. Butler, F. Qi, O. Sorkhabi, and A. G. Suits, J. Phys. Chem. A 104, 11261 (2000); J. Chem. Phys. 114, 4505 (2001).

${ }^{18}$ F. P. Lossing, Can. J. Chem. 50, 3973 (1973); D. W. Minsek and P. Chen, J. Phys. Chem. 94, 8399 (1990).

${ }^{19}$ A. M. Mebel, W. M. Jackson, A. H. H. Chang, and S. H. Lin, J. Am. Chem. Soc. 120, 5751 (1998).

${ }^{20}$ Standard heats of formation for allyl chloride, allene, and $\mathrm{HCl}$ are taken from the NIST Standard Reference Database, no. 69, February 2000, accessed at http://WebBook.nist.gov/chemistry/

${ }^{21}$ P. W. Browning, D. C. Kitchen, M. F. Arendt, and L. J. Butler, J. Phys. Chem. 100, 7765 (1996).

${ }^{22}$ M. L. Morton, F. Qi, J. L. Miller, and L. J. Butler, manuscript in preparation.

${ }^{23}$ J.-F. Riehl and K. Morokuma, J. Chem. Phys. 100, 8976 (1994).

${ }^{24}$ S.-R. Lin, S.-C. Lin, Y.-C. Lee, Y.-C. Chou, I.-C. Chen, and Y.-P. Lee, J. Chem. Phys. 114, 160 (2001).

${ }^{25} \mathrm{~J}$. J. Lin, Y. T. Lee, and X. Yang, private communication of results in preparation for publication in J. Chem. Phys.

${ }^{26} \mathrm{~T}$. Stephenson, private communication of unpublished results.

${ }^{27}$ B. F. Parsons, L. J. Butler, and B. Ruscic, Mol. Phys. (to be published). 